\title{
Timing and ecological priority shaped the diversification of sedges in the Himalayas
}

\author{
Uzma • ${ }^{\text {Corresp., } 1,2,3}{ }^{3}$ Pedro Jiménez-Mejías ${ }^{\text {Corresp., } 4}$, Rabia Amir ${ }^{1}$, Muhammad Qasim Hayat ${ }^{1}$, Andrew L. Hipp ${ }^{2,3}$ \\ 1 Plant Systematics and Evolution Laboratory, Department of Plant Biotechnology, Atta-Ur-Rahman School of Applied Biosciences (ASAB), National \\ University of Sciences and Technology (NUST), Islamabad, Pakistan \\ 2 Herbarium, The Morton Arboretum, Lisle, Illinois, United States of America \\ 3 Pritzker DNA laboratory, The Field Museum, Chicago, Illinois, United States of America \\ 4 Department of Biology (Botany), Universidad Autónoma de Madrid, Ciudad Universitaria de Cantoblanco, Calle Francisco Tomás y Valiente, Madrid, Spain \\ Corresponding Authors: Uzma ., Pedro Jiménez-Mejías \\ Email address: uzma_165@yahoo.com, pjimmej@gmail.com
}

Background. Diversification patterns in the Himalayas have been important to our understanding of global biodiversity. Despite recent broad-scale studies, the most diverse angiosperm genus of the temperate zone-Carex L. (Cyperaceae), with ca. 2100 species worldwide-have not yet been studied in the Himalayas, which contains 189 Carex species. Here the timing and phylogenetic pattern of lineage and ecological diversification were inferred in this ecologically significant genus. We particularly investigated whether priority, adaptation to ecological conditions, or both explain the highly successful radiation of the Kobresia clade (ca. 60 species, of which around 40 are present in the Himalayas) of Himalayan Carex.

Methods. Phylogenetic relationships were inferred using maximum likelihood analysis of two nuclear ribosomal DNA (nrDNA) regions (ITS and ETS) and one plastid gene (matK); the resulting tree was timecalibrated using penalized likelihood and a fossil calibration at the root of the tree. Biogeographical reconstruction for estimation of historical events and ancestral ranges was performed using the dispersal-extinction-cladogenesis (DEC) model, and reciprocal effects between biogeography and diversification were inferred using the geographic state speciation and extinction (GeoSSE) model. Climatic envelopes for all species for which mapped specimen data available were estimated using climatic data from WORLDCLIM, and climatic niche evolution was inferred using a combination of Ornstein-Uhlenbeck models of shifting adaptive optima and maximum likelihood inference of ancestral character states under a Brownian motion model.

Results. The Himalayan Carex flora represents three of the five major Carex clades, each represented by multiple origins within the Himalayas. The oldest Carex radiation in the region, dating to ca. $20 \mathrm{Ma}$, near the time of Himalayan orogeny, gave rise to the now abundant Kobresia clade via long-distance dispersal from the Nearctic. The Himalayan Carex flora comprises a heterogeneous sample of diversifications drawn from throughout the cosmopolitan, but mostly temperate, Carex radiation. Most radiations are relatively recent, but the widespread and diverse Himalayan Kobresia radiation arose at the early Miocene. The timing and predominance of Kobresia in high-elevation Himalayan meadows suggests that Kobresia may have excluded other Carex lineages: the success of Kobresia in the Himalayas, in other words, appears to be a consequence largely of priority, competitive exclusion and historical contingency. 
1 Title: Timing and ecological priority shaped the diversification of sedges in the Himalayas

2 Uzma $^{1,2,3}$, Pedro Jiménez-Mejías ${ }^{4}$, Rabia Amir ${ }^{1}$, Muhammad Qasim Hayat ${ }^{1}$,

3 Andrew L. Hipp 2,3

4 1Plant Systematics and Evolution Laboratory, Department of Plant Biotechnology, Atta-Ur-

5 Rahman School of Applied Biosciences (ASAB), National University of Sciences and

6 Technology (NUST), Sector H-12, Islamabad, Pakistan

$7 \quad{ }^{2}$ Herbarium, The Morton Arboretum, Lisle, Illinois, USA

8 3Pritzker DNA laboratory, The Field Museum, Chicago, Illinois, USA

$9{ }^{4}$ Department of Biology (Botany), Universidad Autónoma de Madrid, Ciudad Universitaria de

10 Cantoblanco, Calle Francisco Tomásy Valiente, 7, 28049 Madrid, Spain

11 Corresponding Authors:

Uzma, uzma_165@yahoo.com; Pedro Jiménez-Mejías,pjimmej@gmail.com

\section{Running title: Diversification of sedges in Himalayas}

14

15 


\section{Abstract}

Background. Diversification patterns in the Himalayas have been important to our understanding of global biodiversity. Despite recent broad-scale studies, the most diverse angiosperm genus of the temperate zone-Carex L. (Cyperaceae), with ca. 2100 species worldwide- have not yet been studied in the Himalayas, which contains 189 Carex species. Here the timing and phylogenetic pattern of lineage and ecological diversification were inferred in this ecologically significant genus. We particularly investigated whether priority, adaptation to ecological conditions, or both explain the highly successful radiation of the Kobresia clade (ca. 60 species, of which around 40 are present in the Himalayas) of Himalayan Carex.

Methods. Phylogenetic relationships were inferred using maximum likelihood analysis of two nuclear ribosomal DNA (nrDNA) regions (ITS and ETS) and one plastid gene (matK); the resulting tree was time-calibrated using penalized likelihood and a fossil calibration at the root of the tree. Biogeographical reconstruction for estimation of historical events and ancestral ranges was performed using the dispersal-extinction-cladogenesis (DEC) model, and reciprocal effects between biogeography and diversification were inferred using the geographic state speciation and extinction (GeoSSE) model. Climatic envelopes for all species for which mapped specimen data available were estimated using climatic data from WORLDCLIM, and climatic niche evolution was inferred using a combination of Ornstein-Uhlenbeck models of shifting adaptive optima and maximum likelihood inference of ancestral character states under a Brownian motion model.

Results. The Himalayan Carex flora represents three of the five major Carex clades, each represented by multiple origins within the Himalayas. The oldest Carex radiation in the region, dating to ca. $20 \mathrm{Ma}$, near the time of Himalayan orogeny, gave rise to the now abundant Kobresia clade via long-distance dispersal from the Nearctic. The Himalayan Carex flora comprises a heterogeneous sample of diversifications drawn from throughout the cosmopolitan, but mostly temperate, Carex radiation. Most radiations are relatively recent, but the widespread and diverse Himalayan Kobresia radiation arose at the early Miocene. The timing and predominance of Kobresia in high-elevation Himalayan meadows suggests that Kobresia may have excluded other Carex lineages: the success of Kobresia in the Himalayas, in other words, appears to be a consequence largely of priority, competitive exclusion and historical contingency. 


\section{Introduction}

The habitat and topographic diversity of mountains make them important centers of biodiversity and rare species endemism (Hughes \& Atchison, 2015; Luo et al., 2016; Myers et al., 2000; Xie et al., 2014; Xing \& Ree, 2017; Yu et al., 2015; Zhang et al., 2014). Topographic diversity of montane regions is expected to provide opportunities for in situ diversification and genetic differentiation (Holzinger et al., 2008; Liu et al., 2016; Matteodo et al., 2013; Pellissier et al., 2010; Villaverde et al., 2015a; Wang \& Bradford, 2014). Numerous studies have highlighted the importance of mountains in the assembly and origin of some of the vital global biodiversity hotspots, such as the Great Cape region (Richardson et al., 2001), the Andes (Hoorn et al., 2010), and Madagascar (Vences et al., 2009).

At the same time, mountain ecosystems are isolated and limited in range, island-like (Carlquist, 1965; Gehrke \& Linder, 2009; Hughes \& Eastwood, 2006), making their biota particularly sensitive to climate change or other environmental perturbations. High-alpine lineages often have only long-distance dispersal and adaptation as options for responding to climate change. Recent studies have reported long-distance dispersals among mountains to be more frequent than formerly assumed (Heaney, 2007; Levin, 2006; Schaefer et al., 2009; Villaverde et al., 2015a). But as global warming threatens to drive many cold-adapted species upslope toward extinction (Chen et al., 2009; Thomas, 2004; Morueta-Holme et al., 2015; though see Crimmins et al., 2011 for an alternative to this traditional climate change scenario), research on the dynamics of species diversification in mountain systems is increasingly relevant.

A significant portion of the world's alpine diversity appears to have originated in the Pliocene and Pleistocene in the wake of late Miocene global cooling (Herbert et al., 2016; Milne $\&$ Abbott, 2002). However, some radiations triggered by the uplift of major mountain ranges seems to be older (Hughes \& Atchison, 2015). For example, while the Tibetan biota exhibit abundant recent diversification (between 0.5 and $15 \mathrm{Ma}$; Renner, 2016), the effects of Tibetan Plateau uplift are reflected in much older divergences in mid-Eocene. By contrast, the cold-adapted biota of the Tibetan Plateau didn't exist before climatic cooling from 13 Ma (Mid-Miocene) onward (Favre et al., 2015). Similarly, uplift of the neighboring Hengduan Mountains had a major effect on in situ diversification of resident lineages traceable to ca. 8 Ma (Xing \& Ree, 2017).

The Himalayas, which adjoin both the Tibetan Plateau and the Hengduan Mountains, are the world's highest and one of its youngest mountain ranges, encompassing a wide ecoclimatic 
94 range (Dobremez, 1976). The rapid orogeny of the Himalayas, which began ca. 59-50 Ma, 95 continues today at a rate of ca. $5 \mathrm{~cm} \mathrm{yr}^{-1}$ (Klootwijk et al., 1992; Patriat \& Achache, 1984; Wang et al., 2012), influencing the topography of adjoining mountain ranges (Rolland, 2002; Xie et al., 2014). The Himalayas range harbours ca. 10,500 plant species from 240 families (Rana \& Rawat, 2017): this high variation in topography and vegetation types (Mani, 1978) makes this range one of the world's biodiversity hotspots. Moreover, the Himalayas constitute a vast cordillera, extending over $2500 \mathrm{~km}$ from the border between Afghanistan and Pakistan in the west to northern Burma and western Yunnan in the east (Searle, 2007), which has had substantial effect on global climate through creation of monsoon conditions in Southeast Asia and the formation of xeric habitats in Central Asia (Wan et al., 2007; Wang et al., 2012; Favre et al., 2015). The Himalayas and adjacent regions are an excellent model for the study of ecologically driven continental species radiations (Acharya et al., 2011; Grytnes \& Vetaas, 2002; Korner, 2000; Price et al., 2011).

Carex L. (Cyperaceae Juss.) is one of the largest angiosperm genera at ca. 2100 species (Global Carex Group, 2015, Léveillé-Bourret et al., 2018) and disproportionately important in the Himalayas, which harbours an estimated 189 species. Four major clades identified in the genus are: core Unispicate, Schoenoxiphium, Vignea and core Carex, which are sister to smaller clade (Siderostictae clade) belong to section Siderostictae and allied species (Global Carex Group, 2016; Starr \& Ford, 2008; Starr et al., 2015; Waterway et al., 2009). Carex (including the previously segregated genera Kobresia and others; Global Carex Group, 2015) has a nearly cosmopolitan distribution, being present on all continents (Hipp et al., 2016), with a center of diversity in the northern temperate regions (Starr et al., 2009). The diversity of Carex in the Himalayas is concentrated in the eastern regions, which harbor 153 species and have higher plant biodiversity in general (Xie et al., 2014), in contrast with the 112 species of the western half (Govaerts et al., 2018+). 40 Carex species are endemic to the Himalayas. The majority of Carex diversity of the Himalayas is represented by species of the core Unispicate clade, in particular species formerly segregated into genus Kobresia (ca. 40 species). The diversity of this clade raises a question as to whether the core Unispicate clade owes much of its diversity to in situ diversification in the Himalayas.

In this study, we address four questions regarding the influence of the Himalayan uplift on the diversification of Carex: (1) Are the timing of lineage and niche diversification in Carex coordinated with uplift of the Himalayas? (2) Is the diversification rate of Carex in the Himalayas 
125 higher than the background rate of diversification for the genus? (3) Is the high diversity of the

126 former genus Kobresia (hereafter we will use Kobresia in this paper) in the Himalayas due to

127 preadaptation to high elevation conditions, clade age (priority effect), or a mixture of both? (4)

128 Are the Himalayas a source of global sedge biodiversity? In order to address all these concerns,

129 the spatial and diversification rates with climatic niche frameworks have been employed. Ours is

130 the first study on the diversification of sedges in the Himalayas, and thus it contributes significantly

131 to our understanding of the origins of biodiversity in this important region of the globe.

132

133 Materials \& Methods

134 Study area and taxa selection

135 For this study, 55 specimens representing 19 species were collected from Western Himalayas 136 range (lies in Pakistan) between 2011 and 2017 (Supplementary Table S1a). The collecting areas 137 were selected as mentioned in Flora of Pakistan by Kukkonen (Kukkonen, 2001) for the genus. 138 All specimens collected by the lead author (U) were submitted to the herbaria of The Morton 139 Arboretum (MOR), Lisle, Illinois, USA and Pakistan Museum of Natural History (PMNH), 140 Islamabad, Pakistan. Additionally, 27 specimens of 21 species received from E (Royal Botanic 141 Garden Edinburgh), MO (Missouri Botanical Garden) and MSB (Botanishche Staatssammiung 142 München) herbaria were also included (Supplementary Table S1b), comprising a total of 40 143 species from the Himalayas from which the new sequences were obtained for this study. 144 Eventually, we retrieved sequences for 944 species distributed worldwide from the Global Carex 145 Group (2016) data matrix (available at Dryad: http://dx.doi.org/10.5061/dryad.k05qb). The final 146 dataset included 56\% (105 species) of Himalayan taxa out of total 189 Himalayan species 147 (Supplementary Table S2). Four outgroup species (Eriophorum vaginatum, Scirpus polystachyus, 148 Trichophorum alpinum and Trichophorum caespitosum) were included from the tribe Scirpeae 149 (Léveillé-Bourret et al., 2014) for phylogenetic analyses. All data and scripts for the analyses are 150 deposited in GitHub (https:/github.com/uzma-researcher/Himalayan-Carex-Diversification; 151 https:/github.com/uzma-researcher/Himalayan-Carex-Climatic-niche-Evolution).

152

\section{Molecular methods}

154 Total genomic DNA was isolated from silica-dried leaves of collected specimens and dried leaves 155 of herbarium specimens using DNeasy Plant Mini Kit (QIAGEN, Valencia, California, USA, 
156 catalog \# 69106) in the laboratory at The Morton Arboretum, Lisle, USA. Amplifications of two

157 nrDNA regions, the internal transcribed spacer (ITS) and 5' end of the external transcribed spacer 158 (ETS), were performed using primer pairs ITS-IF and ITS-4R (Urbatsch et al., 2000; White et al., 159 1990) and ETS-1F and 18S-R (Starr et al., 2003) respectively. The chloroplast (cpDNA) region 160 matK was amplified using two primer pairs: matK-2.1F and matK-5R (Kew Royal Botanic 161 Garden, http://www.kew.org/barcoding/protocols.html) in the first step and matKF-61 and 162 matKR-673 (nested primers; Global Carex Group, 2016) in the second step with slightly increased 163 in annealing temperature (from $45.0^{\circ} \mathrm{C}$ to $51.0^{\circ} \mathrm{C}$ ). The PCR reaction mixture of $25 \mu \mathrm{L}$ contained: 164

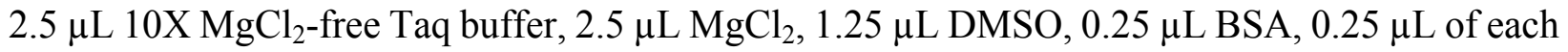
primer at $20 \mathrm{mM}, 0.25 \mu \mathrm{L}$ Taq DNA polymerase (1.25 units), and $1 \mu \mathrm{L}$ of genomic DNA as a template in amplifications of each region. These regions were selected based on suitability for wide-scale as well as fine-scale phylogenetics in the genus (Starr et al., 2003; Starr et al., 2009;

168

169

170

171

172

173

174

175

176

177

178

179

180

181

182

183

184

185

186

Global Carex Group, 2016). Amplification cycles for ITS and ETS regions followed the conditions mentioned by Hipp et al. (2006) with minor adjustment in annealing temperature to get appropriate amplicons. However, two-step amplification of matK region involved PCR conditions: $95.0^{\circ}$ for 1:00; 30 cycles of: $95.0^{\circ}$ for $0: 45,45.0^{\circ}\left(51.0^{\circ}\right.$ for internal region) for $0: 45,72.0^{\circ}$ for $1: 30 ; 72.0^{\circ}$ for 3:00. Amplified regions were cleaned and then sequenced following the conditions as described by Begley-Miller et al. (2014) at Pritzker DNA laboratory, The Field Museum, Chicago, USA.

\section{Phylogenetic analyses and time-calibrated molecular phylogeny}

The resulting new sequences for ETS, ITS and matK regions were edited and assembled in Geneious version 9.1.6 (Biomatters, Auckland, New Zealand, available from http://www.geneious.com). Sequences were aligned for each region with Global Carex Group (2016) sequences using MUSCLE (Edgar, 2004) as implemented in Geneious. The matrices for each region were trimmed or $\mathrm{N}$-filled to maintain equal characters in all sequences. The best-fit models of molecular evolution were determined under seven nucleotide substitution scheme based on the Akaike information criterion implemented in jModelTest2 v.2.1 (Darriba et al., 2008; Table 1). The three DNA regions (ETS, ITS and matK) were first analyzed using maximum likelihood (ML) method as implemented in RAxML HPC-PTHREADS-SSE3 version 8.2.4 (Stamatakis, 2006) with model of evolution GTR $+\mathrm{I}+\mathrm{G}$ (General Time Reversible model with gamma distributions and invariant sites) and node support through 1000 rapid (fast) bootstraps to assess 
187 congruence among these nuclear and chloroplast DNA regions. The three matrices (ETS, ITS and 188 matK matrices) were then concatenated into a single matrix (with gaps or missing data). The

189

190

191

192

193

194

195

196

197

198

199

200

201

202

203

204

205

206

207

208

209

210

211

212

213

214

215

216

217 combined matrix was analyzed using ML in RAxML with model of evolution GTR $+\mathrm{I}+\mathrm{G}$ and 1000 fast bootstraps to assess the phylogenetic relationship of the Himalayan Carex. These phylogenetic analyses were performed using the CIPRES Science Gateway v3.3 platform (Miller et al., 2010).

The Himalayan Carex species were non-monophyletic within each of three major clades (Vignea, core Unispicate, core Carex) in the resulting phylogenetic tree. Therefore, the Shimodaira-Hasegawa (SH) test (Shimodaira \& Hasegawa, 1999) was performed as implemented in RAxML (version 8.2.4) to evaluate how strongly monophyly of Himalayan lineages was rejected, using five separate constraints that represent alternative scenarios for partial or complete monophyly of Himalayan lineages (Supplementary Figure S1; Table S3). Our null hypothesis $\left(\mathrm{H}_{0}\right)$ for each test was polyphyly of Himalayan lineages within the major clade (or taxon set) being tested, while $\mathrm{H}_{\mathrm{a}}$ was monophyly of Himalayan lineages within that clade. The ML tree generated under each constraint was compared to the unconstrained ML tree.

Divergence times were estimated on the ML tree (constructed on the concatenated dataset) after excluding outgroups using penalized likelihood (Sanderson, 2002) as implemented in treePL (Smith \& O'Meara, 2012), which is designed for large phylogenies (Spalink et al., 2016a). We followed Jiménez-Mejías et al. (2016) and employed Carex colwellensis Chandler which was the oldest reliable known fossil ascribable to Carex, dated back to Priabonian, late Eocene. The crown node was fixed at 37.8-33.9 Ma according to previous reconstructions by Miguez et al. (2017), an age compatible with Carex colwellensis (Jiménez-Mejías \& Martinetto, 2013; Jiménez-Mejías et al., 2016). Penalized likelihood calibration was performed after optimizing priming and smoothing values using a $\chi^{2}$ test and cross validation. We assessed run convergence using the "thorough" option and inspected the tree visually using FigTree v1.4.2. The SH test and treePL analyses were performed using supercomputer facility at Research Center for Modeling and Simulation (RCMS), National University of Sciences and Technology (NUST), Islamabad, Pakistan.

\section{Biogeographical distribution and coding}

For biogeographical analyses, we considered division of species into two groups: Himalayan and non-Himalayan, according to their presence or absence in the Himalayas (Supplementary Table S2). Species distributions were based on the World Checklist of Selected Plant Families (Govaerts 
218 et al., 2018+), Flora of Pakistan (Kukkonen, 2001) and Flora of China (Dai et al., 2010). However,

219 many species present predominantly in the Himalayas are also present in adjacent regions, making

220 it difficult to study diversification patterns within the mountains. Therefore, we assessed sensitivity

221 of our analyses to alternative biogeographic coding strategies by coding taxa in two different ways:

222 "narrow sense" biogeographic coding, which treats the Himalayas as following strict Himalayan

223 boundaries; and "broad sense" biogeographic coding, which includes the adjoining mountains

224 (Karakoram, Hindu Kush, Tibet plateau, and Hengduan mountains) as part of a broadly construed

225 Himalayas (Supplementary Table S2). Secondly, to estimate ancestral ranges at the global scale,

226 we scored taxa according to ten ecozones / biogeographical realms based on pattern of endemicity

227 of the genus Carex. However, our coding diverges from traditional coding (Udvardy, 1975) in two

228 regards: (1) we split the Palearctic region into Western and Eastern to separate Europe, north Africa

229 and western Asia from eastern and central Asia; and (2) we treat the Himalayas in the broad sense

230 as a tenth region (biogeographic coding in supplementary Table S4).

231 Georeferenced data for each Carex species available at GBIF data portal

232 (http://www.gbif.org) were retrieved using species synonyms to gather all records under their 233 current taxonomic names (Global Carex Group, 2015), listed in supplementary Table S5. We 234 downloaded GBIF data using the rgbif package (Chamberlain, 2017) in R (R Core Team, 2013).

235 The largest number of records $(17,841)$ was retrieved for species Carex lasiocarpa, followed by 236 Carex canescens with 16,825. 41 species had only one record and around 324 species had fewer 237 than 50 records. We cleaned data to remove specimens georeferenced outside the reported range 238 of the species (according to Govaerts et al., 2018+) and eliminated duplicates using the dismo 239 (Hijmans et al., 2011), ape (Paradis \& Schliep, 2018) and magrittr (Bache \& Wickham, 2016)

240 packages in R. Species data were also thinned to exclude records within 1.0 to $1.6 \mathrm{~km}$ of each other 241 (following Hipp et al., 2018). The post-thinning dataset comprised 965,556 occurrence records for 242850 unique species, each represented by an average of 1,136 specimens.

244 Geographic-dependent diversification and extinction

245 The GeoSSE model (Goldberg et al., 2011) as implemented in the diversitree R package (FitzJohn, 246 2010) was used to assess the historical differences in the rate of speciation, dispersal and extinction 247 in the Himalayas versus non-Himalayas regions in narrow (total 966 species in which 10 endemic 248 to Himalayas, 861 endemic to non-Himalayas while 95 species present in both regions)and broad 
249 (total 966 species in which 51 endemic to Himalayas, 838 non-Himalayas while 77 species present 250 in both regions) sense biogeographic coding (using supplementary Table S2 for geographic states 251 coding to narrow and broad sense coding and resulting dated phylogeny). Diversification rate was 252 estimated in three states: A representing species endemic to the non-Himalayas, B representing 253 species endemic to the Himalayas, and AB representing species present in both regions. In this 254 model, we estimate speciation rates of species in region $\mathrm{A}(\mathrm{sA})$ and $\mathrm{B}(\mathrm{sB})$, as well as sAB, 255 speciation rates for taxa that give rise to two daughter species, one in each region. Likewise, 256 geographical range expansion from $\mathrm{A}$ or $\mathrm{B}$ to $\mathrm{AB}$ were estimated with rates of dispersal $\mathrm{dA}$ and $257 \mathrm{~dB}$ respectively and range contraction with rates of extinction $\mathrm{xA}$ and $\mathrm{xB}$.

258 Full and constrained alternative GeoSSE models were tested: the full model, in which rates 259 of speciation, extinction and dispersal differed among two regions; a constrained model in which 260 speciation in taxa distributed across two regions was set to zero ( $\mathrm{AAB} \sim 0$ ); and a model in which 261 rates of speciation and extinction were constrained to be the same between regions $(\mathrm{sA} \sim \mathrm{sB}$; $\mathrm{xA}$ $262 \sim \mathrm{xB})$. Models were compared using the Akaike Information Criterion. The best-fit model was also 263 fitted using Bayesian Markov chain Monte Carlo (MCMC) for 100,000 generations and an 264 exponential prior to estimate parameter distributions.

265

\section{Biogeographical reconstruction and ancestral range estimation}

267

Biogeographic history was investigated as transitions among the ten regions initially coded, excluding Antarctica and Oceania for computational reasons. The remaining regions were Himalaya, Indo-Malaya, Eastern Palearctic, Western Palearctic, Nearctic, Afrotropic, Neotropic and Australasia. The DEC model was utilized as implemented in Lagrange (Ree et al., 2005; Ree \& Smith, 2008) and BioGeoBEARS (Matzke, 2014) using BSM (Biogeography stochastic mapping). The DEC method implements the maximum-likelihood approach and allows vicariance, range expansion (dispersal) and range contraction (extinction) processes with inclusion of different parameters. The BSM analysis is based on the Bayesian MCMC approach and estimated the biogeographical history of the events (anagenetic and cladogenetic events) along the branches of the tree. In the BSM analysis, in total 1000 stochastic mapping replicates with 50000 maximum trees per branch were conducted on ML tree. The alternative biogeographic model implemented in BioGeoBEARS was not considered, as the inclusion of the jump parameter is not directly 
279 testable relative to non-jump models (Ree \& Sanmartin, 2018) and introduces complexities that

280 are not necessary to explain our biogeographic scenarios.

281

282 Climatic niche modelling

283 To characterize climatic envelopes for the species for which specimen data were available, we 284 extracted 19 bioclimatic variables from WORLDCLIM data using the $\mathrm{R}$ package raster

285

286

287

288

289

290

291

292

293

294

295

296

297

298

299

300

301

302

303

304

305

306

307

308

309 (WorldClim v1.4; Hijmans et al., 2005). The average value for species occurrence data and 19 bioclimatic variables from a total of 965,556 data for 850 unique species were estimated. The obtained data for 838 species were further proceeded after removing outliers from WORLDCLIM data. For each bioclimatic variable, ancestral character states were estimated assuming a Brownian motion trait evolution process using the 'fastAnc' function in phytools (Revell, 2012). Then nonmetric multidimensional scaling (NMDS) ordination was employed using Euclidean distances normalized to unit variance on bioclimatic data for the tips as well as the internal nodes of the tree. The stress from $\mathrm{K}=1$ to $\mathrm{K}=10$ was calculated and plotted stress against dimension to estimate how much additional information was extracted from the bioclimatic data with each additional NMDS axis.

Data were plotted with internal nodes of interest, representing ancestors of Himalayan radiations, colored for identification. The Himalayan taxa of the core Unispicate clade are represented by two major subclades, with Kobresia (40 species) sister to a clade dominated by Uncinia (30 species). Placement of the Kobresia ancestors were compared with ancestors of all other Himalayan radiations to evaluate whether the Kobresia ancestors may have represented an ecologically specialized (preadapted) species to Himalayan climatic conditions. Alternatively, the earlier origin of Kobresia species in the Himalayas would support clade age (priority effect and possibly, competitive exclusion) as an explanation for success of Kobresia relative to other more recent Himalayan radiations. Niche analyses were conducted using the phytools and vegan (Oksanen et al., 2012; Revell, 2012) packages in R.

However, the analysis above presupposes a Brownian motion model of niche evolution, which is unrealistic in the face of natural selection (Butler \& King, 2004; Hansen, 1997). Underparameterizing the model of niche evolution risks inflating Type II error (incorrectly failing to reject the null hypothesis of no difference among clades) if clades tend to adapt to new adaptive regimes to which species migrate. To address this limitation, we also analyzed our niche data using 
310 a multivariate Ornstein-Uhlenbeck (O-U) model implemented in the PhylogeneticEM package of

311 R to test transitions in selective regime in an information theoretic framework (Bastide et al., 2017;

312 Bastide et al., 2018). Analyses were conducted using a scalar O-U process and default search

313 settings for the PhyloEM function in the PhylogeneticEM.

314

315 Results

316 Phylogenetic relationship of Himalayan species and estimation of Himalayan clade

317 divergence in tribe Cariceae

318 New sequences obtained for this study are deposited in GenBank (Supplementary Table S6), and

319 details on each of the DNA matrices are reported in Table 1. The matK tree topology

320 (Supplementary file S1 for matrix) showed low support for most relationships (Supplementary file

321 S2). Similarly, the phylogeny obtained from ITS (Supplementary file S3 for ITS matrix) showed

322 phylogenetic incongruence (Global Carex Group, 2016; Waterway et al., 2009, 2016), with low

323 support for the major clades (Supplementary file S4). The ETS region (Supplementary file S5 for

324 matrix) was mostly well-defined for major clades with high to moderate supports (Supplementary

325 file S6). The three matrices with least missing data for one individual per species were

326 concatenated into a single matrix of 970 sequences (outgroups included) with 2080 sites

327 (Supplementary file S7), containing 48.7\% missing data coded as gaps. The topology of the tree

328 based on combined DNA datasets was highly congruent with previous studies (Global Carex

329 Group, 2016; Waterway et al., 2009, 2016) and supported at most major clades. All the four major

330 clades (Schoenoxiphium, Vignea, core Unispicate and core Carex) sister to Siderostictae clade

331 were recovered (Supplementary file S8). The Himalayan species (105) fall into three major clades

332 of Carex: 1) Vignea, 2) core Unispicate and 3) core Carex. The Himalayan taxa (16 species) in the

333 Vignea clade were largely spread out in the clade, not sister to other Himalayan taxa, though two

334 sister species pairs were observed. Himalayan species in core Unispicate clade (30 species) mainly

335 belong to Kobresia, except for two unrelated species formerly classified under section

336 Leucoglochin, arrayed in two clades: Kobresia clade 1, which exhibited only three species (minor

337 clade), and Kobresia clade 2 (major clade) with 27 Himalayan species (Supplementary file S8).

338 Himalayan taxa (59 species) in core Carex occurred as small clades or isolated (single) species

339 dispersed throughout the clade. Our topology may be poorly supported in some clades, but the 
340 groups and branching we retrieved was fully compatible with the Global Carex Group (2016) tree,

341 where the clades retrieved were more strongly supported.

342 Date calibrations (Supplementary Figure S2) are also congruent with previous reports

343 (Escudero et al., 2012; Waterway et al., 2009; Waterway et al., 2016), which is expected given

344 that they are based on the same sources (performed on ML tree). The earliest Himalayan

345 diversification is the Kobresia radiation in the core Unispicate clade at the early Miocene (around

$34620.6 \mathrm{Ma}$ ), followed by diversifications in core Carex (early Miocene, 14.4 Ma) and Vignea (late

347 Miocene, 7.2 Ma; Table 2) clades. Although all Himalayan taxa diversified in three major clades

348 in the epoch Miocene, however, the timing of diversification of Himalayan Carex was different in

349 three major clades, which suggested multiple origins and also non-monophyletic lineages. Our

350 time calibrations do differ from recent work (Spalink et al., 2016a, b) due to the fact that we use a

351 calibration based on a more recent date, compatible with the fossil record (Jiménez-Mejías et al., 352 2016).

353 Monophyly of the Himalayan taxa within each major clade was strongly rejected at the 3540.01 level based on the Shimodaira-Hasegawa test, except for the Kobresia species in the core 355 Unispicate clade, where monophyly cannot be rejected (Table 3). We focused an additional test on 356 the monophyly of Kobresia, in which Kobresia was constrained to be monophyletic and only the 357 Unispicate taxa included. In this test, monophyly of Kobresia was not significantly rejected $(\Delta \operatorname{lnL}$ $358=-1.32$ ). Thus, while Kobresia was found to be polyphyletic in previous work (Global Carex 359 Group, 2016) and in the current study, we considered this result poorly supported by the data, 360 pending additional study.

361

362

363

\section{Ancestral range reconstruction}

Initial biogeographic reconstruction under the DEC model was conducted on the "narrow sense" (Supplementary file S9) biogeographic coding, which failed to recover any clade endemic to the Himalayas, which is at odds with our observation that numerous species are predominantly 366 Himalayan in origin. We thus present here analysis of data coded in the "broad sense" (see methods; Supplementary file S10), using the stochastic mapping (BSM) method on the DEC model as implemented in BioGeoBEARS. We generated 1000 stochastic maps in every 50000 trees per branch in BSM analysis. In each stochastic map, total event counts of cladogenetic events were 
371 that of anagenetic which were based on only dispersal events (Supplementary Table S7). However,

372 an interesting finding in BSM results was that none of the events showed "range switching 373 dispersal", while all the observed dispersal was of "range expansion".

374 Under the broad sense biogeographic coding through BSM, 128 Himalayan taxa were 375 distributed among three major clades: 1) Vignea $(16 \%), 2)$ core Unispicate (29\%) and 3) core 376 Carex (54.6\%) (Figure 1). The highest number of dispersal events into the Himalayas was obtained 377 from Eastern Palearctic (Mean=39.42; s.d.=5.23) followed by Nearctic (Mean=21.44; s.d.=4.31) 378 and Western Palearctic (Mean=14.48; s.d.=3.63) regions. The lowest number of dispersal events 379 was obtained from three regions into the Himalayas; Neotropic (Mean= 3.60; s.d.=2.47), 380 Australasia $($ Mean= 3.64; s.d.=1.83) and Indo-Malaya (Mean=5.22; s.d.=2.16). The in situ 381 diversification within the Himalayas that leads dispersal from the Himalayas region 382 correspondingly into the Eastern Palearctic with the maximum average dispersal events 383 (Mean=35.26; s.d.=4.11), however, the following two regions were Indo-Malaya and Western 384 Palearctic (Means=12. 88 and 12.48, s.d.=3.31 and 3.72, respectively) (Supplementary Table S7). The oldest colonization into the Himalayas, at the crown of the Kobresia clade (comprising 386 37 Himalayan species out of 128 species in total based on broad sense), occurred during the early Miocene (ca. $20 \mathrm{Ma}$ ). Taxa from the Vignea clade originate from the Nearctic and Western

388 Palearctic and Eastern Palearctic (Figure 1). All origins are reconstructed as arising from relatively 389 recent colonization into the Himalayas (started in late Miocene, ca. 7.2 Ma and last colonization appeared very recently at ca. $0.09 \mathrm{Ma}$ and ca. $0.35 \mathrm{Ma}$ by Carex physodes and Carex canescens, respectively). In the core Unispicate and core Carex clades, by contrast, the Himalayan species cluster into around 12 small clades of 2 to 33 species (Supplementary file S10). The Himalayan species from the core Unispicate clade derived mostly from Nearctic ancestors with one radiation deriving from the Eastern Palearctic (Figure 1, Supplementary file S10). The colonization out of the Himalayas were observed into the Eastern and Western Palearctic, Indo-Malaya, Neotropic, and Nearctic regions around 10 million years ago. While in core Carex, the Himalayan species are arranged in small sub-clades which arose around the early Miocene, there was more recent (ca. 8.5 Ma) in-situ diversification within the Himalayas that ended up pushing species out of it (Supplementary file S10). The ancestral ranges of the Himalayan taxa were predominantly in the Eastern Palearctic, Western Palearctic and Nearctic regions. However, in core Carex, Himalayan 401 taxa arise from these three regions as well as the Afrotropic region (Figure 1). Further, the core 
402 Carex dispersals were inferred from the Himalayas into these four regions and particularly 403 Australasia. However, our sampling was somehow biased towards the Nearctic region, this was a 404 direct consequence of using the Global Carex Group (2016) dataset, which is the largest and most 405 complete Carex dataset to date ( $>50 \%$ of the total diversity).

406

407 Diversification dynamics of Himalayan species

408 Among the three GeoSSE models evaluated with AIC values, the best-fit model (Table 4) for the 409 narrow $(\triangle \mathrm{AIC}=49.94)$ and broad $(\triangle \mathrm{AIC}=76.08)$ sense biogeographic coding was the constrained 410 model in which speciation in taxa distributed across two regions was set to zero ( $\mathrm{sAB} \sim 0$ ). Both 411 biogeographic coding (narrow and broad) strongly reject the model constrained to have speciation 412 rates (sA-sB) equal in the Himalayas and non-Himalayas and extinction rates also equivalent (xA$413 \mathrm{xB}$ ). Given our finding that the broad-sense biogeographic reconstruction recovers Himalayan 414 lineages (see biogeography results above), we considered the broad-sense biogeographic coding 415 to be better suited to estimate diversification rates within versus outside of the Himalayas (Table 416 4). Although the Himalayas showed positive net diversification rate (0.16) there was no real 417 difference in diversification rates between the two areas (0.06). We utilized Bayesian MCMC on 418 the broad sense dataset to estimate uncertainty on parameters (Table 4, Supplementary Figure S3). 419 Figure 2 represents posterior probability differences between the lineages of the two regions and 420 diversification rates; suggests the rate of speciation indeed lower in the Himalayas than non421 Himalayas with difference 0.34, similar finding was obtained with the rate of extinction (0.28).

422 The rate of dispersal was higher in Himalayan than non-Himalayan lineages with difference 0.27; 423 while not significant, this result suggests that independent origins of Himalayan taxa from non424 Himalayan ancestors may be less common than colonization of non-Himalayas from Himalayan 425 radiations (Supplementary Figure S3).

426

\section{Climatic niche evolution}

428 Plotting stress against number of dimensions in a set of initial NMDS ordinations that include data 429 for both the tip states and ancestral reconstructions (Supplementary Figure S4) shows significant 430 decreases in stress up to $K=5$. However, as visual inspection of the 5-dimensional ordination 431 showed no qualitative differences from the 2-dimensional ordinations, ordination results here were 432 presented for the $K=2$ NMDS analysis. For ordination of both the inferred ancestral states (Figure 
433 3A) and the tip states (Figure 3B), eight BIOCLIM variables correlate strongly $(|r|>0.7)$ with $434 \mathrm{MDS}$ axis 1 (BIO1, BIO4, BIO6, BIO9, and $\mathrm{BIO} 11$, which relate to temperature; and $\mathrm{BIO} 12$, $435 \mathrm{BIO} 13$, and $\mathrm{BIO} 16$, which relate to precipitation) and three with MDS axis 2 (BIO14 and BIO17, 436 precipitation of the driest month and quarter respectively; and BIO15, precipitation seasonality, 437 estimated as the coefficient of variation). In the ordination of inferred ancestral states, the two 438 Kobresia clade ancestors were not significantly differentiated from the ancestors of the remaining 439 Himalayan taxa. While the maximum likelihood estimator underlying these reconstructions was 440 biased against detecting differentiation among tips closer to the base of the tree (because the 441 estimator under a Brownian motion process is the weighted mean of all tips in the tree; Felsenstein, 442 1985), the ordination of tip states (Figure 3B) was not biased in this way, and should show 443 differentiation if the Kobresia clade are descended from an ancestor that was uniquely adapted to 444 a different climatic niche. To the contrary, the 95\% C.I. for the Kobresia clade climatic niche was 445 almost entirely contained within the 95\% C.I. for the remaining Himalayan taxa and exhibited a 446 narrower variance, which was expected given that it reflected a narrower phylogenetic diversity 447 (Figure 3B). Both groups were also not significantly differentiated from the remainder of Carex. Analysis using the multivariate scalar O-U model, on the other hand, recovered two major shifts in selective regime: one at the base of the Uncinia clade, which is strongly represented in the Neotropics and New Zealand; and one at the base of a clade comprising primarily of the traditional Indicae and Decorae sections, groups of primary Tropical distribution (Figure 4) for the given data set employed in this study. These clades are characterized respectively by higher temperatures, higher precipitation, and lower seasonality (Uncinia); and higher temperatures, lower precipitation, lower temperature seasonality, and higher precipitation seasonality (Indicae / Decorae clade). Himalayan taxa overall are widespread in climatic niche and exhibit no consistent trend (Supplementary Figure S5).

457

\section{Discussion}

459 Our study demonstrates that Himalayan diversity of the cold-adapted Carex reflects a complex 460 history of migrations and in situ diversification episodes rather than a few distinct radiations within the Himalayas. The dominance of the portion of the core Unispicate clade that includes Kobresia462 the oldest radiation that we detected (early Miocene, $\sim 20 \mathrm{Ma}$ ) - is attributable to priority effect 463 and represents historical contingency upon entry to the Himalayas. This major clade, combined 
464 with diversification of several minor clades and numerous dispersals into the Himalayas, explains

465 the diversity of Himalayan sedges we observe today.

466

\section{Himalayan orogeny and the origin of the Kobresia clade}

468 Carex taxa of the Himalayas exhibited high phylogenetic diversity both among clades - three of 469 the five major Carex clades were represented in the Himalayas - and within clades, where the 470 Himalayan Carex are mostly highly polyphyletic. The divergence time for the largest Himalayan 471 Carex clade, the Kobresia clade, falls in the early Miocene (ca. 20.6 Ma). This postdates the initial 472 uplift of the Himalayas by about 30-39 million years (see introduction above), during which time 473 the Indian Tibetan continent collided with Asian plates. It corresponds well, however, with the 474 second stage of Himalayan uplift (25-20 Ma), at which time accretion of the upper layer of the 475 Indian continental crust further raised the Himalayas (Molnar \& Stock, 2009; van Hinsbergen et 476 al., 2011, 2012). This combination of uplift events introduced the summer monsoon precipitation 477 regime and alpine climates at altitudes of 5000-6500 m (Xie et al., 2014), which might have 478 contributed to migration of floristic elements into the region. Our inference was that the crown 479 diversification of the core Unispicate clade that includes the Kobresia clade may have originated 480 since the timing of this crown diversification was roughly simultaneous with the second Himalayan uplift event, suggests that the dominance of the Kobresia clade among Himalayan Carex was likely due in part to historical contingency in Kobresia assembly to the high alpine Himalayan climate. The Kobresia radiation is singular in its diversity: the remaining Himalayan Carex species arose from 43 migrations into the Himalayas from two other major clades, in which all Himalayan species in Vignea clade lacked Himalayan sisters except two clades of 2 species each; while core Carex Himalayan species also largely lacked Himalayan sisters (25 species), except 10 clades of 2-11 species. Based on age alone, we would expect Kobresia to exhibit higher species diversity than the other Himalayan radiations (Wiens et al., 2009). However, our analyses of multipleregime Ornstein-Uhlenbeck models suggested that there is not special attributes of the Kobresia clade that make it successful in part, but the accident of it just arriving earlier to the unique Himalayan climates. Further, Kobresia exhibited no innate attributes that allowed it to take over the Himalayas. Therefore, our analyses suggested that possibly the contingency (resulted possibly due to historical abiotic events (Fukami, 2015), e.g. uplift of the region during orogeny of the 494 Himalayas) in Kobresia assembly with the combination of clade age (priority effect) and 
495

496

497

498

499

500

501

502

503

504

505

506

507

508

509

510

511

512

513

514

515

516

517

518

519

520

521

522

523

524

525

competitive exclusion (Abrams, 1983; Brown \& Wilson, 1956; Grant \& Grant, 2006; Monroe \& Bokma, 2017; Schluter, 2000) likely explain the success of the Kobresia clade and the floristic dominance of its species in the Himalayas when compared to other Himalayan Carex groups.

\section{Long-distance migration and multiple ancestral ranges}

Previous biogeographic studies in Carex (e.g., Escudero et al., 2009; Hoffmann et al., 2017; Míguez et al., 2017; Spalink et al., 2016b; Villaverde et al., 2015a) have focused on specific clades or broader taxonomic scales. Our study utilizes the broadest phylogenetic sampling of the genus Carex to date (966 species, ca. 50\% of the extant diversity; Figure 1) to address the origins of a highly polyphyletic regional flora, the Carex of the Himalayas. The earliest origin of the Himalayan Carex flora was the Kobresia clade, which arose in the early Miocene from a Nearctic ancestor (Figure 1), presumably by bird-mediated long-distance dispersal (cf. Villaverde et al., 2017b). Such long-distance migrations are well-documented in the genus under diverse scenarios (Escudero et al., 2009; Jiménez-Mejías et al., 2012; Míguez et al., 2017; Villaverde et al., 2015a; Villaverde et al., 2015b; Villaverde et al., 2017a; Villaverde et al., 2017b). There were few radiations out of the Himalayas in this clade to the adjacent Eastern Palearctic and Indo-Malaya as well as to more distant regions (Western Palearctic, Neotropic, and Nearctic). We detected no radiation into the Himalayas from the most adjacent region, Indo-Malaya (Figure 1). Very likely this is due to the fact that Indo-Malaya is dominated by tropical and subtropical dry and moist broadleaf forests, and Carex is a predominantely temperate group (Escudero et al., 2012; Spalink et al., 2018). All these finding were based on the given data set utilized in this study, the inferences would be possibly varied if enhanced the data set with more species.

In the core Carex clade, by far the largest Carex clade globally (Global Carex Group, 2015, 2016), Himalayan species cluster into small clades (2-11 species) and 25 individual species that arose from outside the Himalayas. Ancestral origins for these clades and species are remarkably disparate (Supplementary file S10). Thirty Himalayan species were belonging to the traditional sections Graciles, Decorae, Indicae, Setigerae, Aulocystis, Thuringiaca, Polystachyae, Clandestinae and Radicales derived primarily from Eastern Palearctic ancestors. Twelve Himalayan species from sections Racemosae, Aulocystis, Vesicariae and Phacocystis derived from the Nearctic, while a smaller number of Himalayan species (4) from the traditional Thuringiacae, Spirostachyae, Ceratocystis, and Hallerianae derived from the Western Palearctic. The 
526 Afrotropics seemingly contributed only C. obscuriceps to the Himalayas (Supplementary Figure

527 S3), although this inference may be due to undersampling of the large traditional section

528 Vesicariae. It is similarly striking how many radiations are inferred to have given rise to

529 geographically distant lineages. Dispersals from the Himalayas to the Afrotropic and Australasian

530 region in core Unispicate and core Carex clades bear further investigation.

531

\section{Conclusion}

533 Our analyses demonstrate that Himalayan diversification in the core Unispicate clade has 534 contributed significantly to global sedge diversity. But these also suggest that diversification rates 535 may have been nearly similar within the Himalayas versus non-Himalayas (difference in 536 diversification $=0.06$ ) which were hardly significant. In contrast to studies demonstrating the 537 increased in diversification rate ( 0.4 species per million) to Carex clades sister to Siderostictae 538 clade (Spalink et al., 2016a) and the role of the Himalayas and Hengduan Mountains as engines of 539 global biodiversity (Acharya et al., 2011; Grytnes \& Vetaas, 2002; Liu et al., 2016; Luo et al., 540 2016; Price et al., 2011; Xing \& Ree, 2017; Xie et al., 2014; Wang et al., 2012), our study suggests 541 that the Himalayas have been more nearly an evolutionary dead-end for Carex outside of the core

542 Unispicate clade. The abundance of lineages that have dispersed into the Himalayas and failed to 543 diversify (Figure 1) is remarkable and at odds with our expectations at the outset of the study. It is 544 also somewhat remarkable that dispersal rate out of the Himalayas (0.28 events per million years) 545 is twice as high as diversification rate within the Himalayas ( 0.16 events per million years), and it 546 is perhaps telling that narrow sense biogeographic coding failed to retrieve any clades endemic to 547 the Himalayas.

548 It may well be that Carex outside of the core Unispicate clade has simply been constrained 549 by competitive exclusion from the Kobresia clade, as has been demonstrated in other Himalayan 550 lineages (Kennedy et al., 2012; Price et al., 2011; Price et al., 2014). This effect may become 551 stronger in the future, as Himalayan plant species are driven primarily uphill by warming climate 552 (Padma, 2014). Since ecosystems in the high Himalayas are largely dominated by the species of 553 Kobresia clade, the opportunity for speciation in other Himalayan Carex lineages will be limited, 554 presuming niche conservatism (Wiens \& Graham, 2005). Thus the importance of the Himalayas 555 to global sedge diversity may well be limited primarily to the contribution of the Unispicate sedges. 556 


\section{Acknowledgements}

558 We thank three anonymous reviewers, whose comments have greatly contributed to improving the

559

560

561

562

563

564

565

566

567

568

569

570

571

572

573

574

575

576

577

578

579

580

581

582

583

584

585

586

manuscript. We thank the staff of The Morton Arboretum and The Field Museum for providing assistance in all aspects of this work. In particular we thank Elisabeth Fitzek and Kevin Feldheim for assistance in the lab; Sadia Malik, Enrique Maguilla, Tamara Villaverde, Richard H. Ree, Nicholas Matzke and Joseph W. Brown for advice on analyses; and Marlene Hahn, Andrea Miller and Lindsey Worcester for assistance with curation of data and specimens. We are grateful to Dr. Zahid Ullah, and E, MO and MSB herbaria for providing herbarium plant material.

\section{References}

Abrams, P. (1983). The Theory of Limiting Similarity. Annual Review of Ecology, Evolution, and Systematics, 14, 359-376.

Acharya, B. K., Sanders, N. J., Vijayan, L. \& Chettri, B. (2011). Elevational gradients in bird diversity in the eastern Himalaya: an evaluation of distribution patterns and their underlying mechanisms. PLoS ONE, 6, e29097.

Bache, S. M. \& Wickham, H. (2016). magrittr (version 1.5): A Forward-Pipe Operator for R. https://cran.r-project.org/web/packages/magrittr/index.html.

Bastide, P, Ané, C., Robin, S., \& Mariadassou, M. (2018). Inference of Adaptive Shifts for Multivariate Correlated Traits. Systematic Biology, doi:10.1093/sysbio/syy005.

Bastide, P., Mariadassou, M. \& Robin, S. (2017). Detection of adaptive shifts on phylogenies by using shifted stochastic processes on a tree. Journal of the Royal Statistical Society, 79, 1067-1093.

Begley-Miller, D. R., Hipp, A. L., Brown, B. H., Hahn, M. \& Rooney, T. P. (2014). White-tailed deer are a biotic filter during community assembly, reducing species and phylogenetic diversity. AoB PLANTS, 6(1), plu030.

Bivand, R. \& Lewin-Koh, N. (2013). maptools: tools for reading and handling spatial objects. R package version 0.8-25. Available at: http://CRAN.R-project.org/package=maptools

Brown, W. \& Wilson, E. (1956). Character displacement. Systematic Zoology, 5, 49-64.

Butler, M. \& King, A. A. (2004). Phylogenetic comparative analysis: a modeling approach for adaptive evolution. American Naturalist, 164, 683-695.

Peer] reviewing PDF | (2018:11:32968:2:0:NEW 5 Mar 2019) 
587 Carlquist, S. (1965). Island life. A natural history of the islands of the World. New York, NY, 588 USA: Natural History Press.

589 Chamberlain, S. (2017). rgbif: Interface to the Global 'Biodiversity' Information Facility 'API'. R 590 package version 0.9.8. https://CRAN.R-project.org/package=rgbif

591 Chen, I-C., Shiu, H-J., Benedick, S., Holloway, J. D., Chey, V. K., Barlow, H. S., Hill, J. K. \& 592 Thomas, C. D. (2009). Elevation increases in moth assemblages over 42 years on a tropical 593 594 595 596

597

598

599

600

601

602

603

604

605

606

607

608 mountain. Proceedings of the National Academy of Sciences of the United States of America, 5 (106), 1479-1483.

Crimmins, S. M., Dobrowski, S. Z., Greenberg, J. A., Abatzoglou, J. T. \& Mynsberge, A. R. (2011). Changes in Climatic Water Balance Drive Downhill Shifts in Plant Species' Optimum Elevations. Science, 331, 324-327.

Dai, L. K., Liang, S. Y., Zhang, S. R., Tang, Y. C., Koyama, T. \& Tucker, G. C. (2010). Carex Linnaeus in Flora of China vol. 23, eds. Wu ZY, Raven PH, Hong DY. Science Press and Missouri Botanical Garden Press. Beijing and Saint Louis, pp. 285-461.

Darriba, D., Taboada, G. L., Doallo, R. \& Posada, D. (2012). jModelTest 2: More models, new heuristics and parallel computing. Nature Methods, 9, 772.

Dobremez, J. F. (1976). Le Népal Ecologie et Biogeography, Editions du Centre National de la Recherche Scientifique, Paris, France.

Edgar, R. C. (2004). MUSCLE: A multiple sequence alignment method with reduced time and space complexity. BMC Bioinformatics, 5, 113.

Egorova, T. V. (1999). Sedges (Carex L.) of Russia and adjacent states (within the limits of the former USSR). Saint Louis: Missouri Botanical Garden Press.

609

610

Escudero, M., Hipp, A. L., Waterway, M. J. \& Valente, L. M. (2012). Diversification rates and chromosome evolution in the most diverse angiosperm genus of the temperate zone (Carex,

611 Cyperaceae). Molecular Phylogenetics and Evolution, 63, 650-655.

612

613

614

615

616

617

Escudero, M., Valcárcel, V., Vargas, P. \& Luceño, M. (2009). Significance of ecological vicariance and long-distance dispersal in the diversification of Carex sect. Spirostachyae (Cyperaceae). American Journal of Botany, 96, 2100-2114.

Favre, A., Packert, M., Pauls, S. U., Jahnig, S. C., Uh1, D., Michalak, I. \& Muellner-Riehl, A. N. (2015). The role of the uplift of the Qinghai-Tibetan Plateau for the evolution of Tibetan biotas. Biological Reviews, 90, 236-253. 
618 Felsenstein, J. (1985). Phylogenies and the comparative method. The American Naturalist, 125, 1$619 \quad 15$.

620 FitzJohn, R. G. (2010). Quantitative traits and diversification. Systematic Biology, 59, 619-633.

621 Fukami, T. (2015). Historical Contingency in Community Assembly: Integrating Niches, Species 622 Pools, and Priority Effects. Annual Review of Ecology Evolution and Systematics, 46, 1-23 623 Gehrke, B. \& Linder, H. P. (2009). The scramble for Africa: pan-temperate elements on the 624 African high mountains. Proceedings of the Royal Society B, 276, 2657-2665.

625 Global Carex Group (2015). Making Carex monophyletic (Cyperaceae, tribe Cariceae): A new 626 broader circumscription. Proceedings of the Royal Society of London B: Biological $627 \quad$ Sciences, 179, 1-42.

628 Global Carex Group (2016). Megaphylogenetic specimen-level approaches to the Carex 629 (Cyperaceae) phylogeny using ITS, ETS, and matK sequences: Implications for 630 classification. Systematic Botany, 41, 500-518.

631 Goldberg, E. E., Lancaster, L. T. \& Ree, R. H. (2011). Phylogenetic inference of reciprocal effects 632 between geographic range evolution and diversification. Systematic Biology, 60(4), 451633465

634 Govaerts, R., Jiménez-Mejías, P., Koopman, J., Simpson, D., Goetghebeur, P., Wilson, K., 635 Egorova, T. \& Bruhl, J. (2018+). World Checklist of Cyperaceae. Royal Botanic Gardens, 636 Kew. [online]. Website http://apps.kew.org/wcsp/.

637 Grant, P. \& Grant, B. (2006) Evolution of character displacement in Darwin's finches. Science, $638 \quad 313,224-226$. pmid:16840700

639 Grytnes, J. A. \& Vetaas, O. R. (2002). Species richness and altitude: a comparison between null 640 models and interpolated plant species richness along the Himalayan altitudinal gradient, 641 Nepal. The American Naturalist, 159, 294-304.

642 Hansen, T. F. (1997). Stabilizing selection and the comparative analysis of adaptation. Evolution, $64351,1341-1351$.

644 Heaney, L. R. (2007). Is a new paradigm emerging for oceanic island biogeography?. Journal of 645 Biogeography, 34, 753-757. doi:10.1111/j.1365-2699.2007.01692.x

646 Herbert, T. D., Lawrence, K. T., Tzanova, A., Peterson, L. C., Caballero-Gill, R. \& Kelly, C. S. 647 648 (2016). Late Miocene global cooling and the rise of modern ecosystems. Nature Geoscience, 9, 843-847. 
649 Hijmans, R. J., Cameron, S. E., Parra, J. L., Jones, P. G. \& Jarvis, A. (2005). Very high resolution 650 interpolated climate surfaces for global land areas. International Journal of Climatology, $651 \quad 25,1965-1978$.

652 Hijmans, R. J, Phillips, S., Leathwick, J. \& Elith, J. (2011). Package 'dismo'. Available online at: 653 http://cran.r-project.org/web/packages/dismo/index.html.

654 Hipp, A. L., Jiménez-Mejías, P., Waterway, M. J., Hahn, M. \& Roalson, E. H. (2016). Proceedings 655 Introduction: Phylogeny and Ecological Diversification in Carex. Systematic Botany, $656 \quad 41(3), 498-499$.

657 Hipp, A. L., Manos, P. S., González-Rodríguez, A., Hahn, M., Kaproth, M., McVay, J. D., Avalos, 658 S. V. \& Cavender-Bares, J. (2018). Sympatric parallel diversification of major oak clades 659 660 in the Americas and the origins of Mexican species diversity. New Phytologist, 217(1), 439-452.

661

Holzinger, B., Hulber, K., Camenisch, M. \& Grabherr, G. (2008). Changes in plant species 668 richness over the last century in the eastern Swiss Alps: elevational gradient, bedrock effects and migration rates. Plant Ecology, 195, 179-196.

Hoorn, C., Wesselingh, F. P., ter Steege, H., Bermudez, M. A., Mora, A., Sevink, J., Sanmartin, 671 I., Sanchez-Meseguer, A., Anderson, C. L., Figueiredo, J. P., Jaramillo, C., Riff, D., Negri, F. R., Hooghiemstra, H., Lundberg, J., Stadler, T., Saerkinen, T. \& Antonelli, A. (2010). Amazonia through time: Andean uplift, climate change, landscape evolution, and biodiversity. Science, 330(6006), 927-931.

Hughes, C. E. \& Atchison, G. W. (2015). The ubiquity of alpine plant radiations: from the Andes to the Hengduan Mountains. New Phytologist, 207, 275-282.

Hughes, C. E. \& Eastwood, R. J. (2006). Island radiation on a continental scale: exceptional rates of plant diversification after uplift of the Andes. Proceedings of the National Academy of Sciences, 103, $10334-10339$. 
680 Jiménez-Mejías, P. \& Martinetto, E. (2013). Toward an accurate taxonomic interpretation of Carex

681

682

683

684

685

686

687

688

689

690

691

692

693

694

695

696

697

698

699

700

701

702

703

704

705

706

707

708

709

710 fossil fruits (Cyperaceae): A case study in section Phacocystis in the Western Palearctic. American Journal of Botany, 100, 1580-1603.

Jiménez-Mejías, P., Martín-Bravo, S. \& Luceño, M. (2012). Systematics and taxonomy of Carex sect. Ceratocystis (Cyperaceae) in Europe: A molecular and cytogenetic approach. Systematic Botany, 37, 382-398.

Jiménez-Mejías, P., Martinetto, E., Momohara, A., Popova, S., Smith, S. Y. \& Roalson, E. H. (2016). A commented synopsis of the pre-Pleistocene fossil record of Carex (Cyperaceae). The Botanical Review, 82, 258-345.

Kennedy, J. D., Weir, J. T, Hooper, D. M, Tietze, D. T, Martens, J. \& Price, T. D. (2012). Ecological limits on diversification of the Himalayan core Corvoidea. Evolution, doi:10.1111/j.1558-5646.2012.01618.x

Klootwijk, C. T., Gee, J. S., Peirce, J. W., Smith, G. M. \& Mcfadden, P. L. (1992). An early IndiaAsia contact: palaeomagnetic constrains from Ninetyeast ridge, ODP leg 121. Geology, 20, 395-398.

Korner, C. (2000). Why are there global gradients in species richness? Mountains might hold the answer. Trends in Ecology and Evolution, 15, 513-514.

Kukkonen, I. (2001). Flora of Pakistan, No. 206. Cyperaceae. University of Karachi, Pakistan, and Missouri Botanical Press, St. Louis, Missouri: USA. 277 p.

Léveillé-Bourret, E., Gilmour, C. N., Starr, J. R., Naczi, R. F. C., Spalink, D. \& Systsma, K. J. (2014). Searching for the sister to sedges (Carex): Resolving relationships in CariceaeDulichieae Scirpeae clade (Cyperaceae). Botanical Journal of the Linnean Society, 176, 121.

Léveillé-Bourret, É., Starr, J. R. \& Ford, B. A. (2018). Why are there so many sedges? Sumatroscirpeae, a missing piece in the evolutionary puzzle of the giant genus Carex (Cyperaceae). Molecular Phylogenetics and Evolution, 119, 93-104.

Levin, D. A. (2006). Ancient dispersals, propagule pressure, and species selection in flowering plants. Systematic Botany, 31, 443-448.

Liu, Y., Hu, J., Li, S-H., Duchen, P.,Wegmann, D. \& Schweizer, M. (2016). Sino-Himalayan mountains act as cradles of diversity and immigration centres in the diversification of parrotbills (Paradoxornithidae). Journal of Biogeography, doi:10.1111/jbi.12738 
711 Luo, D., Yue, J-P., Sun, W-G., Xu, B., Li, Z-M., Comes, H. P. \& Sun, H., (2016). Evolutionary

712

713

714

715

716

717

718

719

720

721

722

723

724

725

726

727

728

729

730

731

732

733

734

735

736

737

738

739

740

741 history of the subnival flora of the Himalaya-Hengduan Mountains: first insights from comparative phylogeography of four perennial herbs. Journal of Biogeography, 43, 31-43.

Mani, M. S. (1978). Ecology and Phytogeography of the High Altitude Plants of the Northwest Himalaya. Oxford \& IBH Publishing Company, New Delhi, IN.

Matteodo, M., Wipf, S., Stockli, V., Rixen, C. \& Vittoz, P. (2013). Elevation gradient of successful plant traits for colonizing alpine summits under climate change. Environmental Research Letters, 8, 024043 (10 pp.). http://doi.org/10.1088/1748-9326/8/2/024043

Matzke, N. J. (2014). Model selection in historical biogeography reveals that founder-event speciation is a crucial process in island clades. Systematic Biology, 63, 951-970.

Miguez, M., Gehrke, B., Maguilla, E., Jiménez-Mejıs, P. \& Martın-Bravo, S. (2017). Carex sect. Rhynchocystis (Cyperaceae): a Miocene subtropical relict in the Western Palaearctic showing a dispersal-derived Rand Flora pattern. Journal of Biogeography, doi:10.1111/jbi.13027.

Miller, M. A., Pfeiffer, W. \& Schwartz, T. (2010). Creating the CIPRES Science Gateway for Inference of Large Phylogenetic Trees. Pp. 1-8 in Proceedings of the Gateway Computing Environments Workshop (GCE), 2010 (New Orleans, November 14, 2010).

Milne, R. I. \& Abbott, R. J. (2002). The origin and evolution of tertiary relict floras. Advances in Botanical Research, 38, 281-314.

Molnar, P. \& Stock, J. M. (2009). Slowing of India's convergence with Eurasia since 20 Ma and its implications for Tibetan mantle dynamics. Tectonics, 28, TC3001, doi:10.1029/2008TC002271.

Monroe, M. J. \& Bokma, F. (2017). Does density-dependent diversification mirror ecological competitive exclusion? PLOS ONE, 12(10), e0184814. https://doi.org/10.1371/journal. pone. 0184814

Morueta-Holme, N., Engemann, K., Sandoval-Acuña, P., Jonas, J. D., Segnitz, M. R. \& Svenning, J-C. (2015). Strong upslope shifts in Chimborazo's vegetation over two centuries since Humboldt. Proceedings of the National Academy of Sciences of the United States of America, 112 (41), 12741-12745.

Myers, N., Mittermeier, R. A., Mittermeier, C. G., da Fonseca, G. A. B. \& Kent, J. (2000). Biodiversity hotspots for conservation priorities. Nature, 403, 853-858. 
742 Oksanen, J., Blanchet, F. G., Kindt, R., Legendre, P., Minchin, P. R., O’Hara, B., Simpson, G. L., 743 Henry, M., Stevens, H. \& Wagner, H. (2017). vegan: Community Ecology Package. R

744

745

746

747

748

749

750

751

752

753

754

755

756

757

758

759

760

761

762

763

764

765

766

767

768

769

770

771
URL document]
[WWW https://cran.rproject.org/web/packages/vegan/index.html

Padma, T. V. (2014). Himalayan plants seek cooler climes. Nature, 512, 359 doi:10.1038/512359a

Paradis, E. \& Schliep, K. (2018). ape 5.0: an environment for modern phylogenetics and evolutionary analyses in R. Bioinformatics $\mathrm{xx}$ : $\mathrm{xxx}-\mathrm{xxx}$

Patriat, P. \& Achache J. (1984). India-Eurasia collision and chronology as implications for crustal shortening and driving mechanisms of plates. Nature, 311, 615-621.

Pellissier, L., Fournier, B., Guisan, A. \& Vittoz, P. (2010). Plant traits co-vary with altitude in grasslands and forests in the European Alps. Plant Ecology, 211, 351-365.

Price, T. D., Mohan, D., Tietze, D. T., Hooper, D. M., Orme, C. D. \& Rasmussen, P. C. (2011).

Determinants of northerly range limits along the Himalayan bird diversity gradient. The American Naturalist, 178(Suppl. 1), S97-S108.

Price, T. D., Hooper, D. M., Buchanan, C. D., Johansson, U. S., Tietze, D. T., Alström, P., Olsson, U., Ghosh-Harihar, M., Ishtiaq, F., Gupta, S. K., Martens, J.E., Harr, B., Singh, P. \& Mohan, D. (2014). Niche filling slows the diversification of Himalayan song birds. Nature, $509,222-225$.

Rana, S. K. \& Rawat, G. S. (2017). Database of Himalayan Plants Based on Published Floras during a Century. Data, 2, 36, doi:10.3390/data2040036

R Core Team (2013). R: A language and environment for statistical computing. R Foundation for Statistical Computing, Vienna, Austria. URL http://www.R-project.org/.

Ree, R. H. \& Sanmartín, I. (2018). Conceptual and statistical problems with the DEC + J model of founder-event speciation and its comparison with DEC via model selection. Journal of Biogeography, doi: 10.1111/jbi.13173

Ree, R. H. \& Smith S. A. (2008). Maximum likelihood inference of geographic range evolution by dispersal, local extinction, and cladogenesis. Systematic Biology, 57, 4-14.

Ree, R. H., Moore, B. R., Webb, C. O. \& Donoghue, M. J. (2005). A likelihood framework for inferring the evolution of geographic range on phylogenetic trees. Evolution, 59, 22992311. 
772 Renner, S.S. (2016). Available data point to a 4-km-high Tibetan Plateau by 40 Ma, but 100

773

774

775

776

777

778

779

780

781

782

783

784

785

786

787

788

789

790

791

792

793

794

795

796

797

798

799

800

801

802

molecular-clock papers have linked supposed recent uplift to young node ages. Journal of Biogeography, 43, 1479-1487.

Revell, L. J. (2012). phytools: an R package for phylogenetic comparative biology (and other things). Methods in Ecology and Evolution, 3, 217-223.

Richardson, J. E., Weitz, F. M., Fay, M. F., Cronk, Q. C. B., Linder, H. P., Reeves, G. \& Chase, M. W. (2001). Rapid and recent origin of species richness in the cape flora of South Africa. Nature, 412(6843), 181-183.

Rolland, Y. (2002). From intra-oceanic convergence to post-collisional evolution: example of the India-Asia convergence in NW Himalaya, from Cretaceous to present. Journal of the Virtual Explorer, 8, 193-216.

Sanderson, M. J. (2002). Estimating absolute rates of molecular evolution and divergence times: a penalized likelihood approach. Molecular Biology and Evolution, 19 (1), 101-109.

Schaefer, H., Heibl, C. \& Renner, S. S. (2009). Gourds afloat: a dated phylogeny reveals an Asian origin of the gourd family (Cucurbitaceae) and numerous oversea dispersal events. Proceedings of the Royal Society, 276, 843-851. (doi:10.1098/rspb.2008.1447)

Schluter, D. (2000). Ecological Character Displacement in Adaptive Radiation. The American Naturalist, 156, S4-S16

Searle, M. P. (2007). Diagnostic features and processes in the construction and evolution of OmanZagros-, Himalayan-, Karakoram-, and Tibetan-type orogenic belts, in Hatcher, R.D., Jr., Carlson, M.P., McBride, J.H., and Martínez Catalán, J.R., eds., 4-D Framework of Continental Crust: Geological Society of America Memoir 200, p. 41-61, doi: 10.1130/2007.1200(04).

Shimodaira, H. \& Hasegawa, M. (1999). Multiple comparisons of log-likelihoods with applications to phylogenetic inference. Molecular Biology and Evolution, 16, 1114-1116.

Smith, S. A. \& O'Meara, B. C. (2012). Divergence time estimation using penalized likelihood for large phylogenies. Bioinformatics, 28 (20), 2689-2690.

Spalink, D., Drew, B. T., Pace, M. C., Zaborsky, J. G., Li, P., Cameron, K. M., Givnish, T. J. \& Sytsma, K. J. (2016a). Evolution of geographical place and niche space: Patterns of diversification in the North American sedge (Cyperaceae) flora. Molecular Phylogenetics and Evolution, 95, 183-195.

Peer) reviewing PDF | (2018:11:32968:2:0:NEW 5 Mar 2019) 
803 Spalink, D., Drew, B. T., Pace, M. C., Zaborsky, J. G., Starr, J. R., Cameron, K. M., Givnish, T. J.

804

805

806

807

808

809

810

811

812

813

814

815

816

817

818

819

820

821

822

823

824

825

826

827

828

829

830

831

832

\& Sytsma, K. J. (2016b). Biogeography of the cosmopolitan sedges (Cyperaceae) and the area-richness correlation in plants. Journal of Biogeography, 43, 1893-1904.

Spalink, D., Pender, J., Escudero, M., Hipp, A. L., Roalson, E. H., Starr, J. R., Waterway, M. J., Bohs, L. \& Sytsma, K. J. (2018). The spatial structure of phylogenetic and functional diversity in the United States and Canada: An example using the sedge family (Cyperaceae). Journal of Systematics and Evolution, doi: 10.1111/jse.12423.

Stamatakis, A. (2006). RAxML-VI-HPC: Maximum likelihood-based phylogenetic analyses with thousands of taxa and mixed models. Bioinformatics, 22, 2688-2690.

Starr, J. R. \& Ford, B. A. (2008). Phylogeny and Evolution in Cariceae (Cyperaceae): Current Knowledge and Future Directions. The Botanical Review, 75(1), 110-137.

Starr, J. R., Harris, S. A. \& Simpson, D. A. (2003). Potential of the 5' and 3' ends of the intergenic spacer (IGS) of rDNA in the Cyperaceae: New sequences for lower-level phylogenies in sedges with an example from Uncinia Pers. International Journal of Plant Sciences, 164, 213-227.

Starr, J. R., Janzen, F. H. \& Ford, B. A. (2015). Three new, early diverging Carex (Cariceae, Cyperaceae) lineages from East and Southeast Asia with important evolutionary and biogeographic implications. Molecular Phylogenetics and Evolution, 88, 105-20.

Starr, J. R., Naczi, R. F. C. \& Chouinard, B. N. (2009). Plant DNA barcodes and species resolution in sedges (Carex, Cyperaceae). Molecular Ecology Resources, 9 (Supplement 1), 151163.

Thomas, C. D., Cameron, A., Green, R. E., Bakkenes, M., Beaumont, L. J., Collingham, Y. C., Erasmus, B. F., De Siqueira, M. F., Grainger, A., Hannah, L., Hughes, L., Huntley, B., Van Jaarsveld, A. S., Midgley, G. F., Miles, L., Ortega-Huerta, M. A., Peterson, A. T., Phillips, O. L. \& Williams, S. E. (2004). Extinction risk from climate change. Nature, 427, 145148.

Udvardy, M. D. F. (1975). A classification of the biogeographical provinces of the world. International union for conservation of nature and natural resources. Morges: Switzerland. Urbatsch, L. E., Baldwin, B. G. \& Donoghue, M. J. (2000). Phylogeny of coneflowers and relatives (Heliantheae: Asteraceae) based on nuclear rDNA internal transcribed spacer (ITS) sequences and chloroplast DNA restriction site data. Systematic Botany, 25, 539-565.

Peer) reviewing PDF | (2018:11:32968:2:0:NEW 5 Mar 2019) 
833 van Hinsbergen, D. J. J, Lippert, P. C., Dupont-Nivet, G., McQuarrie, N., Doubrovine, P.V., 834 Spakman, W. \& Torsvik, T. H. (2012). Greater India Basin hypothesis and a two-stage 835 Cenozoic collision between India and Asia. Proceedings of the National Academy of 836 Sciences of the United States of America, 109, 7659-7664.

837 van Hinsbergen, D. J. J, Steinberger, B., Doubrovine, P. V. \& Gassmöller, R. (2011) Acceleration 838 and deceleration of India-Asia convergence since the Cretaceous: Roles of mantle plumes 839 and continental collision. Journal of Geophysical Research, 116,B06101.

Vences, M., Wollenberg, K. C., Vieites, D. R. \& Lees, D. C. (2009). Madagascar as a model region 841 of species diversification. Trends in Ecology and Evolution, 24(8), 456-465.

842 843 844 845 846 847 848 849 850

851

852 853

854

855 856

857

858 859 860

861 862

Villaverde, T, Escudero, M., Martín-Bravo, S., Bruederle, L. P., Luceño, M. \& Starr, J. R. (2015a). Direct long-distance dispersal best explains the bipolar distribution of Carex arctogena (Carex sect. Capituligerae, Cyperaceae). Journal of Biogeography, 42, 1514-1525.

Villaverde, T., Escudero, M., Luceño, M. \& Martín-Bravo, S. (2015b). Long-distance dispersal during the middle-late Pleistocene explains the bipolar disjunction of Carex maritima (Cyperaceae). Journal of Biogeography, 42, 1820 -1831.

Villaverde, T., Escudero, M., Martín-Bravo, S. \& Luceño, M. (2017b). Two independent dispersals to the Southern Hemisphere to become the most widespread bipolar Carex species: Biogeography of C. canescens (Cyperaceae). Botanical Journal of the Linnean Society, $183,360-372$.

Villaverde, T., González-Moreno, P., Rodríguez-Sánchez, F. \& Escudero, M. (2017a). Niche shifts after long-distance dispersal events in bipolar sedges (Carex, Cyperaceae). American Journal of Botany, 104, 1765-1774.

Wan, S., Li, A. C., Clift, P. D. \& Stuut, J. B. W. (2007). Development of the East Asian monsoon: mineralogical and sedimentological records in the northern South China Sea since 20 Ma. Palaeogeogr Palaeoclimatol Palaeoecol, 254, 561-582.

Wang, I. J. \& Bradburd, G. S. (2014). Isolation by environment. Molecular Ecology, 23, 56495662.

Wang, L., Schneider, H., Zhang, X-C. \& Xiang, Q-P. (2012). The rise of the Himalaya enforced the diversification of SE Asian ferns by altering the monsoon regimes. BMC Plant Biology, $12,210$.

Peer] reviewing PDF | (2018:11:32968:2:0:NEW 5 Mar 2019) 
863 Waterway, M. J., Hoshino, T. \& Masaki, T. (2009). Phylogeny, species richness, and ecological

864

865

866

867

868

869

870

871

872

873

874

875

876

877

878

879

880

881

882

883

884

885

886

887

888

889 specialization in Cyperaceae tribe Cariceae. The Botanical Review, 75, 138-159.

Waterway, M. J., Martins, K. T., Dabros, A., Prado, A. \& Lechowicz, M. J. (2016). Ecological and Evolutionary Diversification within the Genus Carex (Cyperaceae): Consequences for Community Assembly in Subarctic Fens. Systematic Botany, 41(3), 558-579.

White, T. J., Bruns, T., Lee, S. \& Taylor, J. (1990). Amplification and direct sequencing of fungal ribosomal RNA genes for phylogenetics. Pp 315-322 in PCR protocols: a guide to methods and amplifications, eds. M. Innis, D. Gelfand, J. Sninsky, and T. White. San Diego: Academic.

Wiens, J. J. \& Graham, C. H. (2005). Niche Conservatism: Integrating Evolution, Ecology, and Conservation Biology. Annual Review of Ecology, Evolution, and Systematics, 36, 519539.

Wiens, J. J., Sukumaran, J., Pyron, R. A. \& Brown, R. M. (2009). Evolutionary and biogeographic origins of high tropical diversity in Old World frogs (Ranidae). Evolution, 63:1217-1231.

Xie, H., Ash, J. E., Linde, C. C., Cunningham, S. \& Nicotra, A. (2014). Himalayan-Tibetan Plateau Uplift Drives Divergence of Polyploid Poppies: Meconopsis Viguier (Papaveraceae). PLoS ONE, 9(6), e99177, doi:10.1371/journal.pone.0099177.

Xing, Y. W. \& Ree, R. H. (2017). Uplift-driven diversification in the Hengduan mountains, a temperate biodiversity hotspot. Proceedings of the National Academy of Sciences of the United States of America, Doi/10.1073/pnas.1616063114

Yu, W-B., Liu, M-L., Wang, H., Mill, R.R., Ree, R.H., Yang, J-B. \& Li, D-Z. (2015). Towards a comprehensive phylogeny of the large temperate genus Pedicularis (Orobanchaceae), with an emphasis on species from the Himalaya-Hengduan Mountains. BMC Plant Biology, 15, 176. DOI 10.1186/s12870-015-0547-9.

Zhang, M-L., Meng, H-H., Zhang, H-X., Vyacheslav, B. V. \& Sanderson, S. C. (2014). Himalayan Origin and Evolution of Myricaria (Tamaricaeae) in the Neogene. PLoS ONE, 9(6), e97582, doi:10.1371/journal.pone.0097582 


\section{Figure 1}

Biogeographical reconstruction of Himalayan Carex.

DEC analysis on broad sense dataset used dated phylogeny (966 species and times in millions of years (Ma)) representing biogeographical history of ancestral ranges in Himalayan Carex lineages designated in three major clades (Vignea, core Unispicate and core Carex). Here at tips of the branches, geographical ranges for extant taxa are labeled, while the outer colored circles represent five major clades (Siderostictae, Schoenoxiphium, Vignea, core Unispicate and core Carex). The colored blocks at internal nodes show ancestral ranges. The pink colored branches designate Himalayan taxa. The map denotes 8 biogeographic ranges with color scheme (Western Palearctic, Eastern Palearctic, Nearctic, Afrotropic, Neotropic, Australasia, Indo-Malaya, Himalaya). 


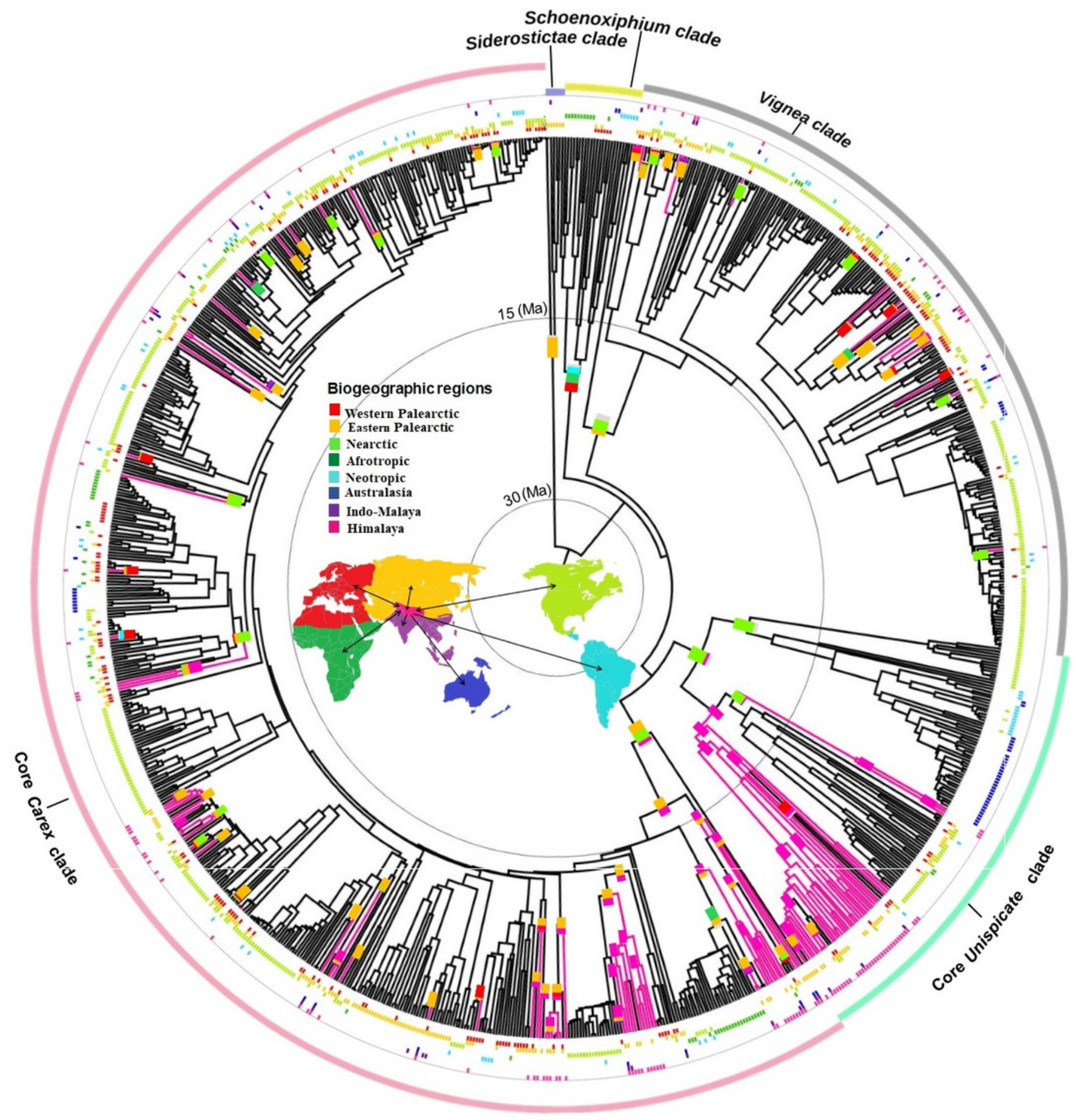


Figure 2 (on next page)

Diversification rates for Himalayan Carex lineages estimated under the model Geographic State Speciation and Extinction (GeoSSE).

The differences in rates of speciation, extinction, and dispersal in Himalayan lineages verse non-Himalayan lineages, are estimated. The Himalayan lineages show higher dispersal rate than non-Himalayan species, however, speciation and extinction rates instead lower in Himalayan lineages compared to non-Himalayan species. The horizontal bars below each curve represent $95 \%$ confidence interval $(\mathrm{Cl})$ under MCMC. 


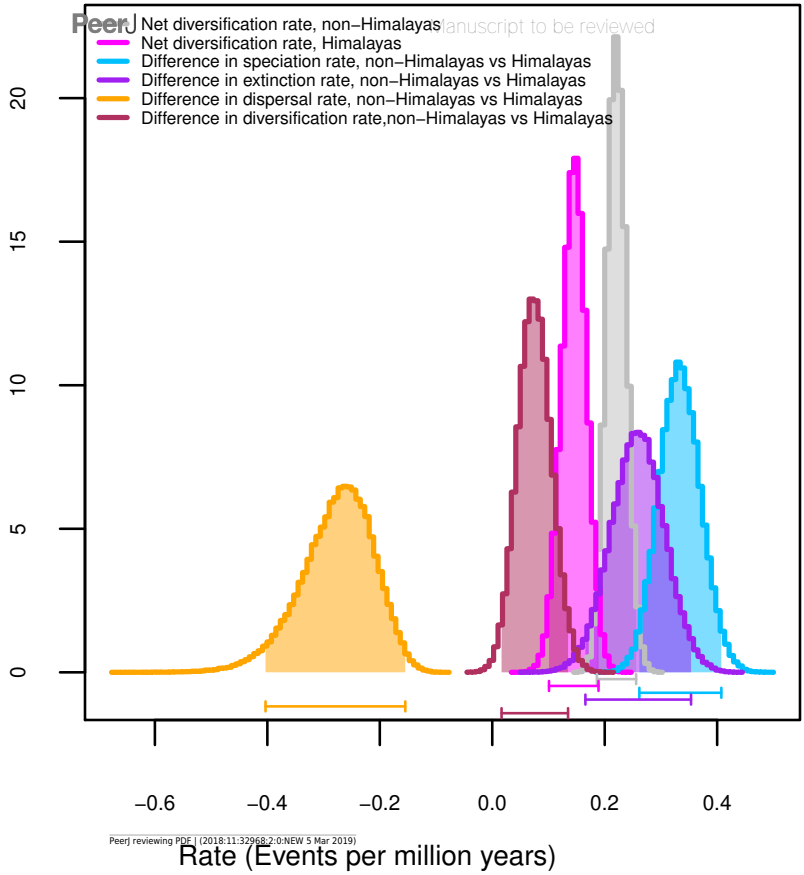


Figure 3

Multidimensional scaling (MDS) analysis to infer Himalayan Carex ancestral and tip states.

Ordination of ancestral states (A) and the tip states (B) of the Himalayan and non-Himalayan for bioclimatic variable $\mathrm{BIO} 12$, mean annual precipitation. Here the $95 \%$ confidence interval (C.I.) for the Kobresia clade climatic niche exhibits a narrower variance for the remaining taxa. 

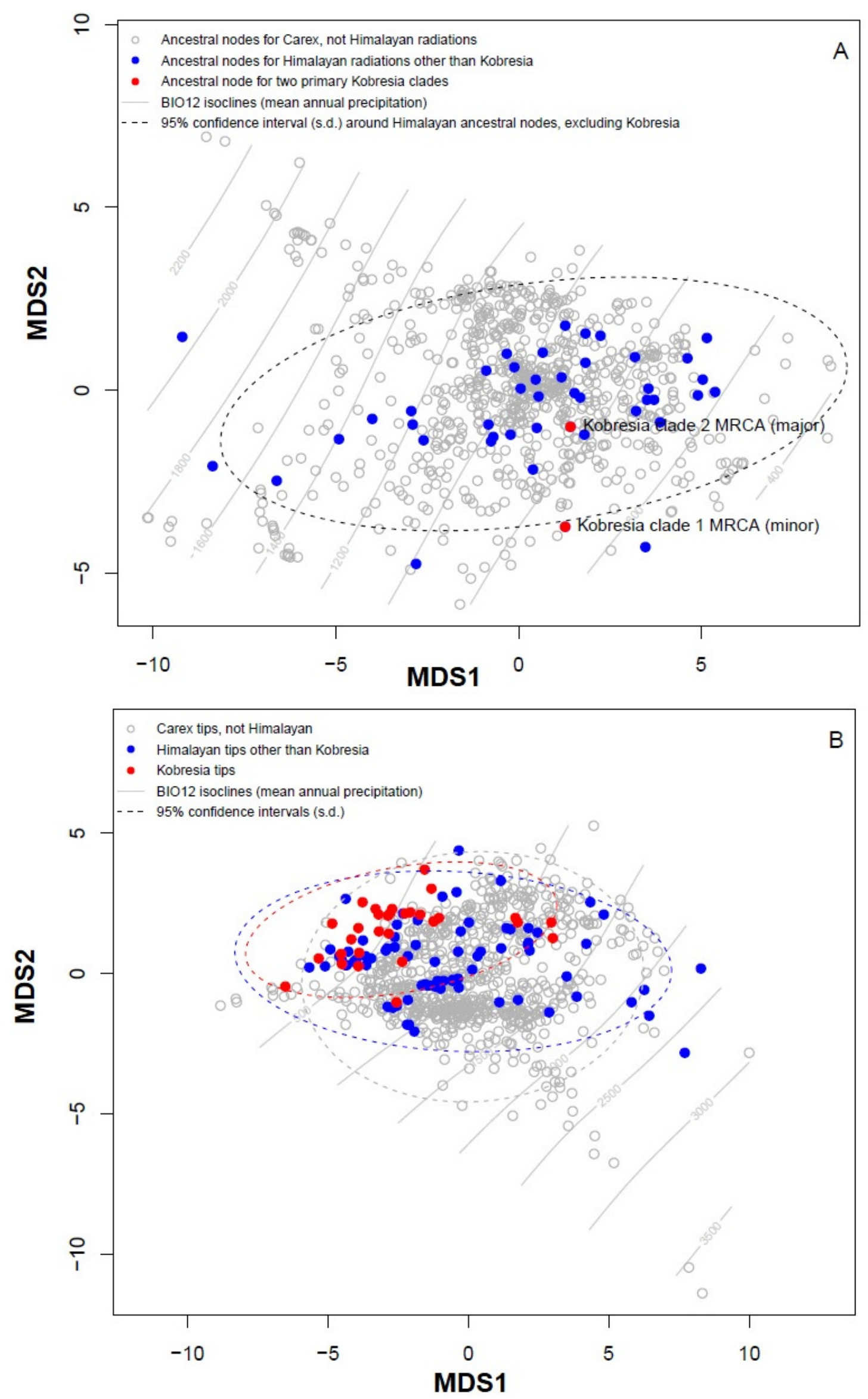


\section{Figure 4}

Climatic niche evolution for range shift in Himalayan taxa using Ornstein-Uhlenbeck (OU) model.

Species range shift in ecological space estimated on $\mathrm{K}=2$ MDS ordination using multivariate scalar O-U model. Here colors changes indicate significant transitions in climatic space and identifies two major shifts: a) at the base of the Uncinia clade and b) at the base of a clade comprised primarily of the traditional sections, Indicae and Decorae. 

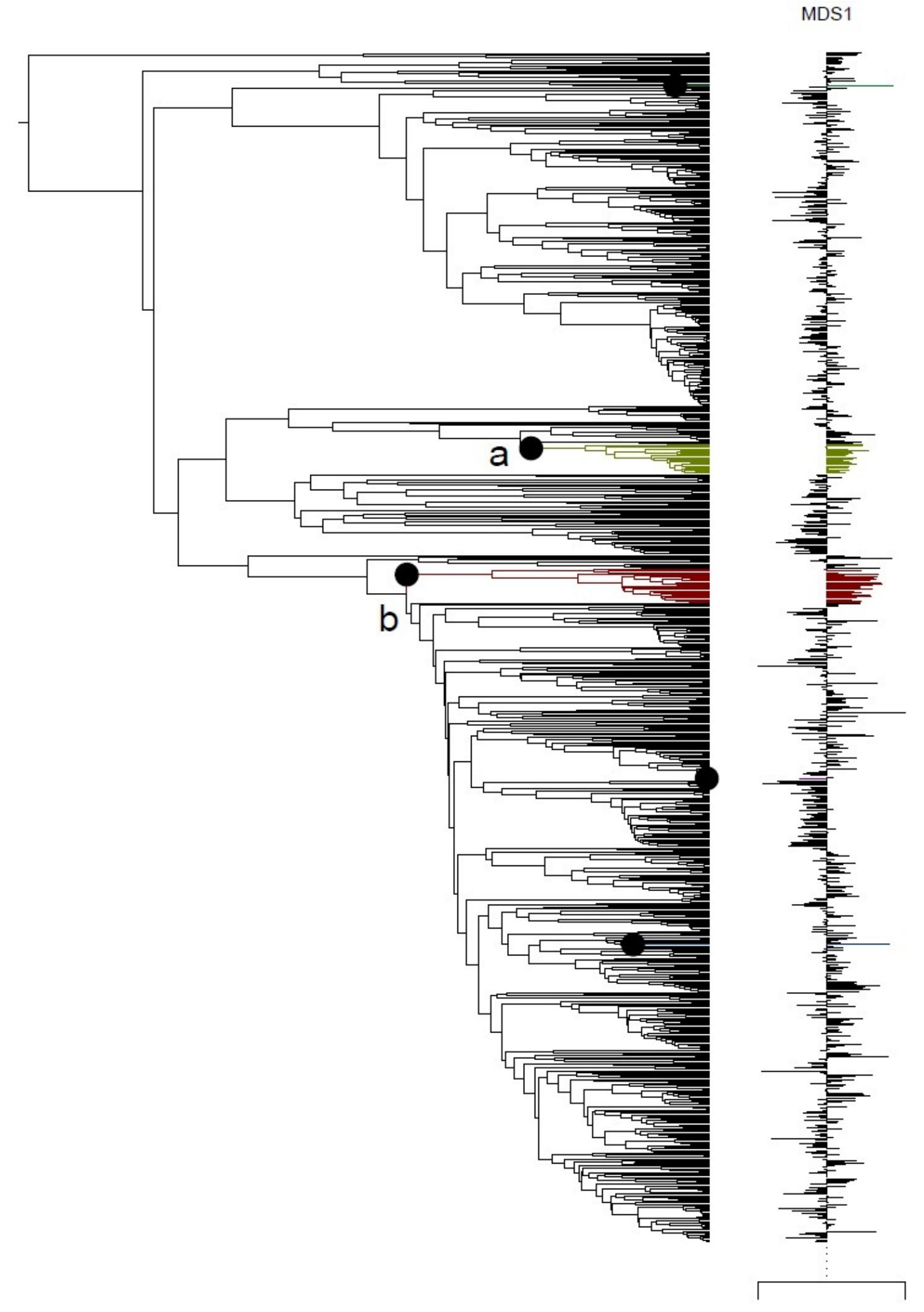

MDS2

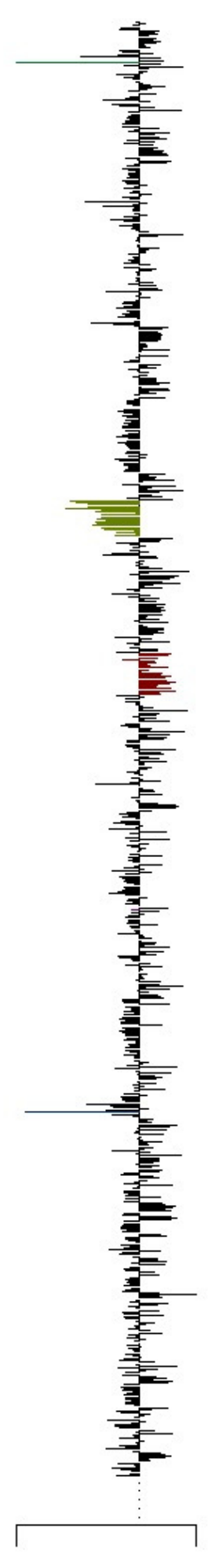

$-8.82$

$10-11.38$

5.27 


\section{Table $\mathbf{1}$ (on next page)}

Total number of taxa, alignment length/total character or sites, number of informative characters, and models of evolution for each DNA region studied in phylogenetic analyses 
1 Table 1 Total number of taxa, alignment length/total character or sites, number of 2 informative characters, and models of evolution for each DNA region studied in phylogenetic 3 analyses

\begin{tabular}{llll}
\hline DNA regions studied & ETS & ITS & matK \\
\hline Total number of taxa & 915 & 892 & 772 \\
Alignment length/total characters or sites & 777 & 783 & 520 \\
Number of informative characters & 501 & 359 & 190 \\
Models of evolution AIC & GTR $+\mathrm{I}+\mathrm{G}$ & $\mathrm{GTR}+\mathrm{I}+\mathrm{G}$ & $\mathrm{GTR}+\mathrm{I}+\mathrm{G}$ \\
\hline
\end{tabular}

4

5

6 
Table 2 (on next page)

Divergence time estimates based on penalized likelihood calibration 
1 Table 2 Divergence time estimates based on penalized likelihood calibration

\begin{tabular}{lcccc}
\hline Clades & $\begin{array}{c}\text { Number of } \\
\text { species in } \\
\text { each clade }\end{array}$ & $\begin{array}{c}\text { Crown } \\
\text { age (Ma) }\end{array}$ & $\begin{array}{c}\text { Himalayan } \\
\text { clades }\end{array}$ & $\begin{array}{c}\text { Geological } \\
\text { time period } \\
\text { divergence (Ma) } \\
\text { ca }\end{array}$ \\
\hline Siderostictae & 6 & 17.2 & & \\
Schoenoxiphium & 24 & 19.4 & & \\
Vignea & 236 & 23.8 & 7.2 & Late Miocene \\
Core Unispicate & 132 & 24.0 & 20.6 & Early Miocene \\
Core Carex & 571 & 22.9 & 14.4 & Early Miocene \\
Core Unispicate -core Carex & 703 & 26.5 & & \\
\hline
\end{tabular}

2

3 


\section{Table 3 (on next page)}

The Shimodaira-Hasegawa (SH) tests, evaluating monophyly of Himalayan lineages

Constraint tree $1=$ Himalayan species in Vignea clade are monophyletic, Constraint tree $2=$ Himalayan species in core Unispicate clade are monophyletic, Constraint tree $3=$ Himalayan species in core Carex clade are monophyletic, Constraint tree $4=$ Himalayan species in core Carex, core Unispicate and Vignea clades are monophyletic, Constraint tree $5=$ All Kobresia species are monophyletic 
1 Table 3 The Shimodaira-Hasegawa (SH) tests, evaluating monophyly of Himalayan

2 lineages

\begin{tabular}{cccccc}
\hline $\begin{array}{c}\text { Topologies of } \\
\text { False tree }\end{array}$ & $\begin{array}{c}\mathbf{l n L}, \\
\text { constrained }\end{array}$ & $\begin{array}{c}\mathbf{I n L}, \\
\text { unconstrained }\end{array}$ & $\begin{array}{c}\text { delta } \mathbf{l n L} \\
(\mathbf{\delta})=(\mathbf{A})-(\mathbf{B})\end{array}$ & s.d. & P \\
\hline Constraint tree 1 & -24701.56 & -23096.69 & -1605.48 & 104.30 & $\mathrm{P}<0.01$ \\
Constraint tree 2 & -17317.09 & -16888.41 & -427.60 & 46.52 & $\mathrm{P}<0.01$ \\
Constraint tree 3 & -52849.70 & -50206.00 & -2644.64 & 167.53 & $\mathrm{P}<0.01$ \\
Constraint tree 4 & -84061.72 & -79483.50 & -4577.86 & 231.26 & $\mathrm{P}<0.01$ \\
Constraint tree 5 & -7496.76 & -7495.88 & -1.32 & 10.96 & non-significant \\
\hline Constraint tree 1 & & & & & \\
\hline
\end{tabular}

3 Constraint tree $1=$ Himalayan species in Vignea clade are monophyletic

4 Constraint tree $2=$ Himalayan species in core Unispicate clade are monophyletic

5 Constraint tree $3=$ Himalayan species in core Carex clade are monophyletic

6 Constraint tree $4=$ Himalayan species in core Carex, core Unispicate and Vignea clades are

7 monophyletic

8 Constraint tree $5=$ All Kobresia species are monophyletic 


\section{Table 4 (on next page)}

Estimates of diversification in Himalayan vs non-Himalayan lineages using Geographic State Speciation and Extinction (GeoSSE) models.

In these models, the Himalayas construed broadly or narrowly (see methods) is denoted as area $\mathrm{B}$; areas outside the Himalayas are denoted as area $A$. Abbreviations: $\ln L=\log$ likelihood; $A I C=$ Akaike Information Criterion; $S A, S B=$ speciation rate in area $A, B ; S A B=$ speciation rate in taxa whose distribution includes both areas $A$ and $B ; d A, d B=\operatorname{dispersal}$ from area $A$ to $B$ or $B$ to $A$ respectively; $x A, x B=$ extinction rate in area $A, B$. 


\begin{tabular}{|c|c|c|c|c|c|c|c|c|c|c|c|c|}
\hline \multirow{2}{*}{$\begin{array}{l}\text { Biogeo- } \\
\text { graphic } \\
\text { coding }\end{array}$} & \multirow[t]{2}{*}{ Models } & \multirow[t]{2}{*}{$-\ln L$} & \multirow[t]{2}{*}{ AIC } & \multirow[t]{2}{*}{$\mathbf{s A}$} & \multirow[t]{2}{*}{$\mathbf{s B}$} & \multirow[t]{2}{*}{$\mathbf{S A B}$} & \multirow[t]{2}{*}{ dA } & \multirow[t]{2}{*}{ dB } & \multirow[t]{2}{*}{$\mathbf{x A}$} & \multirow[t]{2}{*}{$\mathbf{x B}$} & \multicolumn{2}{|c|}{ Net diversification rate } \\
\hline & & & & & & & & & & & $\begin{array}{l}\text { Region A } \\
\text { SA-xA }\end{array}$ & $\begin{array}{r}\text { Region B } \\
\text { sB-xB }\end{array}$ \\
\hline \multirow[t]{3}{*}{$\begin{array}{l}\text { Narrow } \\
\text { sense }\end{array}$} & $\begin{array}{l}\text { Reduced full } \\
(\mathrm{sA}, \mathrm{sB}, \mathrm{dA}, \mathrm{dB}, \mathrm{xA}, \mathrm{xB})\end{array}$ & 2673.88 & 5361.76 & 0.50 & 0.16 & 0 & 0.01 & 0.60 & 0.30 & $1.00 \mathrm{E}-05$ & 0.20 & 0.16 \\
\hline & $\begin{array}{l}\text { Constrained } 1 \\
(\mathrm{sAB} \sim 0)\end{array}$ & 2673.88 & 5359.76 & 0.50 & 0.16 & $\mathbf{0}$ & 0.01 & 0.60 & 0.30 & $\mathbf{0}$ & 0.20 & 0.16 \\
\hline & $\begin{array}{l}\text { Constrained } 2 \\
(\mathrm{sA} \sim \mathrm{sB}, \mathrm{xA} \sim \mathrm{xB})\end{array}$ & 2699.9 & 5409.79 & 0.49 & 0.49 & $9.00 \mathrm{E}-06$ & 0.02 & 3.15 & 0.42 & 0.42 & 0.07 & 0.07 \\
\hline \multirow[t]{3}{*}{$\begin{array}{l}\text { Broad } \\
\text { sense }\end{array}$} & $\begin{array}{l}\text { Reduced full } \\
(\mathrm{sA}, \mathrm{sB}, \mathrm{dA}, \mathrm{dB}, \mathrm{xA}, \mathrm{xB})\end{array}$ & 2715.04 & 5444.09 & 0.50 & 0.16 & $9.00 \mathrm{E}-06$ & 0.009 & 0.28 & 0.28 & $2.00 \mathrm{E}-06$ & 0.22 & 0.16 \\
\hline & $\begin{array}{l}\text { Constrained } 1 \\
(\mathrm{sAB} \sim 0)\end{array}$ & 2715.04 & 5442.08 & 0.50 & 0.16 & 0 & 0.009 & 0.28 & 0.28 & 0 & 0.22 & 0.16 \\
\hline & $\begin{array}{l}\text { Constrained } 2 \\
(\mathrm{sA} \sim \mathrm{sB}, \mathrm{xA} \sim \mathrm{xB})\end{array}$ & 2754.08 & 5518.16 & 0.40 & 0.40 & 0 & 0.01 & 0.19 & 0.17 & 0.17 & 0.23 & 0.23 \\
\hline
\end{tabular}

